\title{
In vitro oxidative decarboxylation of free fatty acids to terminal alkenes by two new P450 peroxygenases
}

Huifang $X u^{1,2}$, Linlin Ning ${ }^{1,2,4}$, Wenxia Yang ${ }^{1,2}$, Bo Fang ${ }^{1,2}$, Cong Wang ${ }^{1,2}$, Yun Wang ${ }^{2,3}$, Jian $X_{u^{2,3}}$, Severine Collin ${ }^{5}$, Frederic Laeuffer ${ }^{5}$, Laurent Fourage ${ }^{5}$ and Shengying $\mathrm{Li}^{1,2^{*}}$

\begin{abstract}
Background: P450 fatty acid decarboxylases represented by the unusual CYP152 peroxygenase family member $\mathrm{OleT}_{\text {JE }}$ have been receiving great attention recently since these P450 enzymes are able to catalyze the simple and direct production of 1-alkenes for potential applications in biofuels and biomaterials. To gain more mechanistic insights, broader substrate spectra, and improved decarboxylative activities, it is demanded to discover and investigate more P450 fatty acid decarboxylases.

Results: Here, we describe for the first time the expression, purification, and in vitro biochemical characterization of two new CYP152 peroxygenases, CYP-Aa162 and CYP-Sm46 29 , that are capable of decarboxylating straight-chain saturated fatty acids. Both enzymes were found to catalyze the decarboxylation and hydroxylation of a broad range of free fatty acids $\left(C_{10}-C_{20}\right)$ with overlapping substrate specificity, yet distinct chemoselectivity. CYP-Sm46 29 works primarily as a fatty (lauric) acid decarboxylase (66.1 $\pm 3.9 \%$ 1-undecene production) while CYP-Aa162 more as a fatty (lauric) acid hydroxylase (72.2 $\pm 0.9 \%$ hydroxy lauric acid production). Notably, the optical spectroscopic analysis of functional CYP-Sm46 $\triangle 29$ revealed no characteristic P450 band, suggesting a unique heme coordination environment. Active-site mutagenesis analysis showed that substitution with the proposed key decarboxylation-modulating residues, His 85 and Ile170, enhanced the decarboxylation activity of CYP-Aa162 and P450 ${ }_{B S \beta}$, emphasizing the importance of these residues in directing the decarboxylation pathway. Furthermore, the steady-state kinetic analysis of CYP-Aa162 and CYP-Sm46 229 revealed both cooperative and substrate inhibition behaviors which are substrate carbon chain length dependent.
\end{abstract}

Conclusions: Our data identify CYP-Sm46 29 as an efficient OleT JE $^{-l i k e}$ fatty acid decarboxylase. Oxidative decarboxylation chemoselectivity of the CYP152 decarboxylases is largely dependent upon the carbon chain length of fatty acid substrates and their precise positioning in the enzyme active site. Finally, the kinetic mode analysis of the enzymes could provide important guidance for future process design.

Keywords: Alkenes, Biofuels, P450 fatty acid decarboxylases, Substrate specificity, Chemoselectivity, Site-directed mutagenesis, Enzyme kinetics

\section{Background}

Cytochrome P450 (CYP) enzymes are a superfamily of important biocatalysts that perform an extraordinary

\footnotetext{
*Correspondence: lishengying@qibebt.ac.cn

${ }^{1}$ Shandong Provincial Key Laboratory of Synthetic Biology, Qingdao Institute of Bioenergy and Bioprocess Technology, Chinese Academy of Sciences, No. 189 Songling Road, Qingdao 266101, Shandong, China Full list of author information is available at the end of the article
}

breadth of biochemical reactions [1-3], and have been widely applied to oxidation of complex organic substrates and biosynthesis of chemical building block molecules [4-6]. Among diverse P450 products, terminal alkenes (i.e., $\alpha$-alkenes or 1-alkenes) have significant industrial potential and outstanding economic importance, given that these hydrocarbons highly mimic the chemical composition and physical properties of fossil fuels 
[7-10]. There has been widespread biotechnological interest focusing on the identification and reconstitution of enzymes and pathways capable of synthesizing biohydrocarbons in microbial hosts [7, 9, 11-17]. A sustainable biosynthetic route to 1-alkenes from biologically abundant feedstocks such as free fatty acids (FFAs) clearly represents a promising pathway. In 2011, Rude et al. [13] reported the first one-step enzymatic oxidative decarboxylation of FFAs by a $\mathrm{P} 450$ peroxygenase $\mathrm{OleT}_{\mathrm{IE}}$, isolated from Jeotgalicoccus sp. ATCC 8456, to yield long-chain $\left(\mathrm{C}_{13}-\mathrm{C}_{19}\right)$ 1-alkenes.

In view of its tremendous potential for biological production of terminal olefins, OleT $\mathrm{JE}_{\mathrm{E}}$ since its discovery has captured great attention within academia and industry. A fast growing number of studies have been carried out to optimize $\mathrm{OleT}_{\mathrm{IE}}$ catalysis and to understand its catalytic mechanism [16, 18-28]. These include the development of alternative catalytic systems (e.g., the $\mathrm{O}_{2} / \mathrm{NAD}(\mathrm{P}) \mathrm{H} /$ redox partners system [16] and the light-driven $\mathrm{H}_{2} \mathrm{O}_{2}$ generation system [21]) (Scheme 1), the determination of OleT $_{\mathrm{IE}}$ crystal structures $[18,28]$, the elucidation of catalytically reactive species $[19,20]$, and the expansion of substrate scope to structurally different aromatic carboxylic acids [29], dionic acids (to produce dienes) [30], and even some unnatural substrates including styrene, nonane, and cyclohexane [31].

Mechanistically, a majority of P450s use $\mathrm{O}_{2}$ and $\mathrm{NAD}(\mathrm{P}) \mathrm{H}$-dependent redox systems to catalyze diverse oxidative/monooxygenation reactions [32, 33]. However, there are a small number of P450s that evolved to naturally utilize $\mathrm{H}_{2} \mathrm{O}_{2}$ as the sole oxygen and electron donor to catalyze oxidative reactions through the socalled peroxide shunt pathway [33-35]. These enzymes are referred to as $\mathrm{P} 450$ peroxygenases. The best-characterized P450 peroxygenases are among the CYP152 [36] family members, including $\mathrm{P}^{2} 50_{\mathrm{BS} \beta}$ (CYP152A1) from Bacillus subtilis [35] and $\mathrm{P}^{450} 0_{\mathrm{SP} \alpha}$ (CYP152B1) from Sphingomonas paucimobilis [34]. OleT ${ }_{\mathrm{IE}}$, based on its amino acid sequence similarity, was designated as CYP152L1 [13, 18]. Within the CYP152 members that have been biochemically characterized so far, $\mathrm{P} 450_{\mathrm{SP} \alpha}$ catalyzes exclusively the C $\alpha$ hydroxylation of FFAs [34], and $\mathrm{P} 450_{\mathrm{BS} \beta}$ generates both $\alpha$ - and $\beta$-hydroxy fatty acids as major products but with a small amount of 1-alkene as well [13, 35, 37]. A recently characterized CYP-MP peroxygenase [24] is able to introduce the hydroxyl group at $\alpha_{-}^{-}, \beta-, \gamma^{-}, \delta_{-}$, and $\varepsilon$-positions of $\mathrm{C}_{12}-\mathrm{C}_{18}$ fatty acids, but it only displayed marginal decarboxylation activity against myristic acid $\left(\mathrm{C}_{14}\right)$ and palmitic acid $\left(\mathrm{C}_{16}\right)$. Heretofore, $\mathrm{OleT}_{\mathrm{JE}}$ is the only one to predominantly catalyze the decarboxylation of long-chain fatty acids generating 1 -alkenes as the major products and $\alpha$ - and $\beta$-hydroxy fatty acids as the side products (Scheme 1) [13, 16, 22]. It would be of great interest and importance to explore more P450 fatty acid decarboxylases and expand the enzyme inventory for future broader biotechnological applications.

In an attempt to screen for biocatalysts capable of converting medium-chain $\mathrm{C}_{12}$ fatty acid (lauric acid) to 1-undecene for potential applications in biofuels and biolubricants, two new P450 sequences, CYPAa162 (CYP152A8, GenBank Accession Number: WP_008340313) from Alicyclobacillus acidocaldarius LAA1 and CYP-Sm46 (CYP152L2, GenBank Accession Number: EKU50422) from Staphylococcus massiliensis S46, were identified apart from $\mathrm{OleT}_{\mathrm{JE}}$ and $\mathrm{P} 450_{\mathrm{BS} \beta}$. To better harness these two uncharacterized CYP152 family members for future industrial applications, and to further our understanding of the unique decarboxylation mechanism employed by CYP152 decarboxylases, we sought to characterize the detailed biochemical properties of the two enzymes.

In this study, we cloned, expressed, and purified CYP-Aa162 and CYP-Sm46 enzymes and in vitro characterized their catalytic activities towards a panel of different carbon chain length fatty acid substrates. Analytical data demonstrated that CYP-Aa162 acts mainly as a P450 ${ }_{\mathrm{BS} \beta}$-like fatty acid hydroxylase, whereas CYP-Sm 46 acts as an efficient $\mathrm{OleT}_{\mathrm{IE}}$-like fatty acid decarboxylase. Their substrate conversion rates and regio- and chemoselectivity exhibited significant substrate carbon chain length dependence. In addition, our enzymatic kinetic

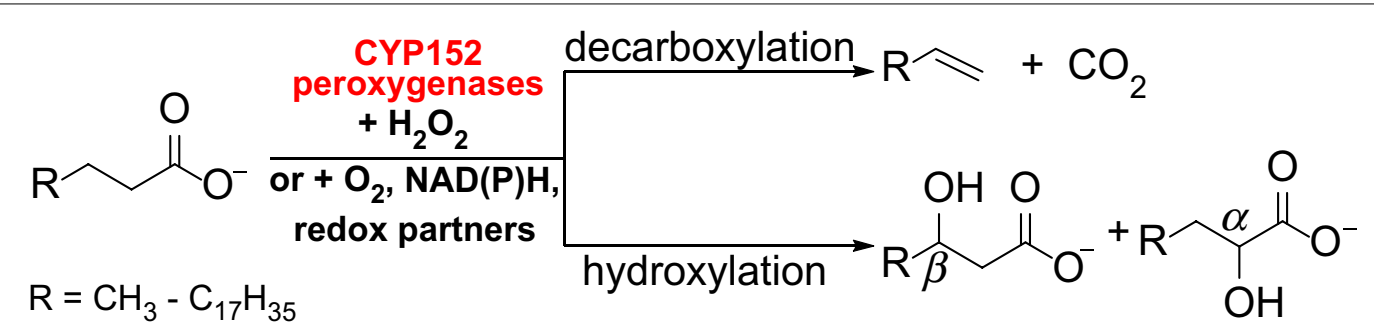

Scheme 1 Fatty acid decarboxylation and hydroxylation catalyzed by CYP152 peroxygenases 
analysis suggested that the metabolism of fatty acids by the CYP152 enzymes could undergo both cooperative and substrate inhibition behaviors, providing important information and guidance for future process design.

\section{Results}

\section{Heterologous expression and purification of CYP-Aa162} and CYP-Sm $46 \Delta 29$

According to protein sequence alignment (Additional file 1: Figure S1), CYP-Aa162 has 64\% (39\%) sequence identity to $\mathrm{P} 450_{\mathrm{BS} \beta}\left(\mathrm{OleT}_{\mathrm{JE}}\right)$, while CYP-Sm46 is $65 \%$ (37\%) identical to $\mathrm{OleT}_{\mathrm{JE}}\left(\mathrm{P}^{4} 50_{\mathrm{BS} \beta}\right)$. Heterologous expression of CYP-Aa162 in E. coli (with its encoding sequence codon-optimized) led to an appreciable level of the recombinant protein purified to near homogeneity (Additional file 1: Figure S2). However, for CYP-Sm46, the original construct of pET28b-CYP-Sm46 (codonoptimized) showed very poor expression and solubility, which did not improve upon subcloning into an alternative expression vector pCWori [38] or by optimization of the expression conditions. This prompted us to re-examine the protein sequence of EKU50422 and its annotation. We found that this sequence has an extra long ( 29 amino acids) $N$ terminus with no functional annotations when compared with most other CYP152 members including those cytochrome P450 family proteins from other Staphylococcus species (Additional file 1: Figure S1). Analyses of the CYP-Sm46 protein sequence using several protein prediction tools such as Phobius, TMHMM 2.0, and SignalP 4.1 [39-41] also showed no positive return of either a signal peptide or transmembrane helices within the $N$-terminal region of 60 amino acids. A further BLAST search revealed a recently added
(17-Jan-2015) 'truncated' entry of CYP-Sm46 (GenBank Accession Number: WP_039990689), hereafter called CYP-Sm $46 \Delta 29$, which decodes from an alternative start codon (GUG) and therefore has the $29 \mathrm{~N}$-terminal amino acids removed. Subsequent expression of this shorter version CYP-Sm $46 \Delta 29$ led to significantly improved protein production and solubility, and the protein was then purified to near homogeneity (Additional file 1: Figure S2). The codon-optimized gene sequences of CYP-Aa162 and CYP-Sm $46 \Delta 29$, and their corresponding amino acid sequences are shown in Additional file 2.

\section{UV-visible spectroscopic properties of CYP-Aa162 and CYP-Sm46 29}

The resting ferric form of CYP-Aa162 (Fig. 1a) exhibited a typical low-spin (LS) water-bound $\mathrm{P} 450$ heme spectrum with its Soret absorption peak at $417 \mathrm{~nm}$ and the smaller $\alpha$ - and $\beta$-bands in the visible region at $~ 566$ and $\sim 538 \mathrm{~nm}$, respectively. These values are similar to those of $\operatorname{OleT}_{\text {IE }}(418,535,566 \mathrm{~nm})$ [18] and other LS bacterial P450s (e.g., the heme domain of CYP102A1 (P450 ${ }_{\mathrm{BM} 3}$ ) from Bacillus megaterium with maxima at 418,534 , and $568 \mathrm{~nm}$ ) [42]. However, CYP-Aa162 displayed no obvious hyperporphyrin (split Soret) characteristic at $\sim 360 \mathrm{~nm}$, which is different from that of $\mathrm{OleT}_{\mathrm{JE}}$ [18]. A widely accepted criterion for the identification of cytochrome P450 is a Soret peak at around $450 \mathrm{~nm}$ in the reduced CO difference spectrum. Here, for CYP-Aa162, both the reduced $\mathrm{CO}$ difference spectrum and the absolute absorption spectrum of the dithionite-reduced $\mathrm{Fe}^{2+}-\mathrm{CO}$ adducts featured a characteristic thiolate-ligated P450 Soret band at $447-448 \mathrm{~nm}$ (Fig. 1a and inset), which is similar to that of $\mathrm{P} 450_{\mathrm{BS} \beta}$ with a peak at $446 \mathrm{~nm}$ [35].
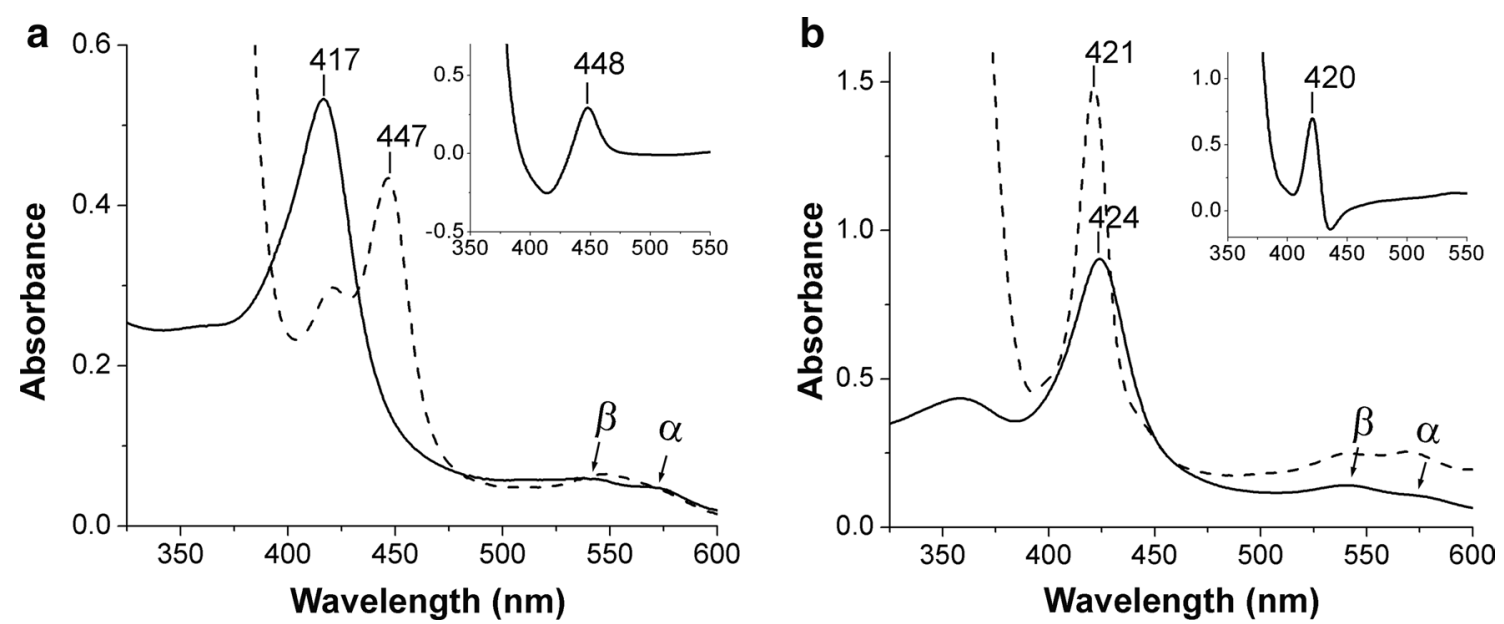

Fig. 1 UV-visible spectra of CYP-Aa162 (a) and CYP-Sm46 $\triangle 29$ (b). The purified enzymes were diluted in $50 \mathrm{mM} \mathrm{NaH}_{2} \mathrm{PO}_{4}(\mathrm{pH} 7.4) \mathrm{containing}$ $300 \mathrm{mM} \mathrm{NaCl}$ and $10 \%$ glycerol, respectively. Spectra are shown for the oxidized ferric form of the CYPs (solid lines) and the $\mathrm{Na}_{2} \mathrm{~S}_{2} \mathrm{O}_{4}-$ reduced ferrous-CO complex of the CYPs (dashed lines). Insets show the reduced CO difference spectrum of each enzyme 
However, the purified ferric form of CYP-Sm $46 \Delta 29$ displayed a red-shifted Soret band at $422-424 \mathrm{~nm}$, followed by a small but prominent $\beta$ band at $540 \mathrm{~nm}$ and a significantly weaker and flat $\alpha$ band at $571 \mathrm{~nm}$ (Fig. 1b). Prominent hyperporphyrin characteristics (split Soret) are visible at $360 \mathrm{~nm}$. These features are similar to those reported for CYP-MP (maxima at 422, 545, and $575 \mathrm{~nm}$ ) [24], but different from the typical 418, 535, and $\sim 568 \mathrm{~nm}$ maxima for LS water-bound P450s [18, 42]. These altered spectroscopic features may indicate an imidazole-coordinated or more likely a distal hydroxylcoordinated ferric LS heme form as suggested in the CYP-MP [24]. Furthermore, much to our surprise, reduction of the CYP-Sm $46 \Delta 29$ with sodium dithionite in the presence of $\mathrm{CO}$ revealed no characteristic $\mathrm{P} 450$ peak at $\sim 450 \mathrm{~nm}$. The maximum absorption of this $\mathrm{Fe}^{2+}-$ $\mathrm{CO}$ adduct was still at $\sim 421 \mathrm{~nm}$ with enhanced $\alpha$ - and $\beta$-bands. Correspondingly, the reduced $\mathrm{CO}$ difference spectrum of CYP-Sm $46 \Delta 29$ also exhibited only the P420 peak (Fig. 1b inset). Attempts to produce a detectable P450 species by altering the amount of dithionite, buffer $\mathrm{pH}$, and by substrate-aided stabilization of any, if exists, P450-CO adduct as the case with P450 EpoK enzyme [43] all proved negative (Additional file 1: Figure S3). The similar ' $\mathrm{P} 420$ ' spectra were observed in all preparations of the enzyme unanimously. These data suggest that CYPSm $46 \Delta 29$ is somehow incapable of forming a detectable cysteine thiolate-ligated $\mathrm{Fe}^{2+}-\mathrm{CO}$ adduct. We speculate that this unusual spectroscopic feature may arise either from simple protonation of the proximal cysteine thiolate to a neutral thiol form $[43,44]$, or from dissociation of the thiolate ligand from the heme iron, followed by coordination of an alternative proximal ligand such as a histidine in the case with the pressure-induced $\mathrm{P} 420_{\text {cam }}$ $[45,46]$, or from other reduction-linked structural alterations that prevent the formation of thiolate-ligated ferrous-CO species. Nevertheless, these altered spectroscopic features did not affect the enzyme's peroxygenase activity as shown below.

\section{Inability of CYP-Aa162 and CYP-Sm $46 \Delta 29$ to elicit monooxygenase activity}

To check if a class I electron transfer system could afford a P450 Soret feature in CYP-Aa162 and CYP-Sm $46 \Delta 29$ [47], we examined the UV-visible spectra of the two enzymes in an $\mathrm{NAD}(\mathrm{P}) \mathrm{H} /$ redox proteins/CO system. As a result, while the control P450 monooxygenase $\mathrm{P} 40_{\mathrm{BM} 3}$ was successfully reduced by the addition of $\mathrm{NADPH}$ and exhibited an almost complete transition to P450 spectrum in the presence of lauric acid (LA) substrate (Additional file 1: Figure S4), neither CYP-Aa162 nor CYP-Sm46 $\Delta 29$ showed a P450 chromophore after incubation with the redox partner proteins $\mathrm{CamAB}$ (i.e., putidaredoxin reductase and putidaredoxin that are able to support the in vitro activity of both $\mathrm{P} 450$ enzymes, see below) and their optimal cofactor NADH in the presence of LA (Fig. 2a). Further catalytic activity assay indicated that the two enzymes exhibited appreciable LA conversion activity in the $\mathrm{H}_{2} \mathrm{O}_{2}$ system. However, their activity was dramatically diminished in the $\mathrm{O}_{2} / \mathrm{CamAB} / \mathrm{NADH}$ reaction system when high concentrations of catalase were added to remove $\mathrm{H}_{2} \mathrm{O}_{2}$ potentially generated from the decoupling of NADH oxidation (Fig. 2b), implying that CYP-Aa162 and CYP-Sm $46 \Delta 29$ have very little or
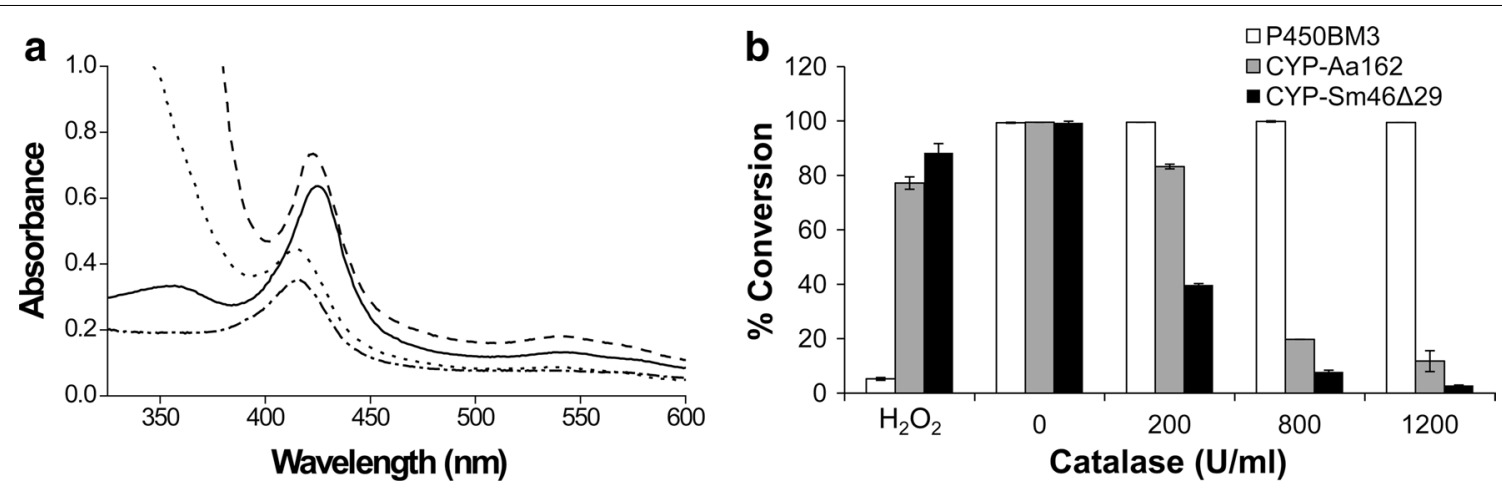

Fig. 2 UV-visible spectra and lauric acid (LA) conversion activity of CYP-Aa162 and CYP-Sm46 29 in the $\mathrm{O}_{2} /$ redox partners/NAD(P)H system. a The UV-visible spectra are, respectively, shown for the substrate LA-bound ferric form of CYP-Sm46 $\triangle 29$ with a Soret band at $422 \mathrm{~nm}$ (solid line); the CamAB/NADH'reduced' CO-bound form of CYP-Sm46 $\triangle 29$ with the Soret peak still at $\sim 422 \mathrm{~nm}$ (dashed line); the substrate LA-bound ferric form of CYP-Aa162 with a Soret band at $418 \mathrm{~nm}$ (dashed and dotted line); the CamAB/NADH'reduced' CO-bound form of CYP-Aa162 with an unshifted Soret peak (dotted line). b Enzymatic conversion of lauric acid by CYP-Aa162, CYP-Sm46 229 , and the control P450 ${ }_{\mathrm{BM} 3}$ monooxygenase in the $\mathrm{O}_{2} /$ redox proteins/NAD(P)H system in the absence or presence of different concentrations of catalase. For CYP-Aa162 and CYP-Sm46 29 , CamAB/ $\mathrm{NADH}$ was used for the electron transfer cascade. For the self-sufficient $\mathrm{P}_{450_{\text {Вм}}}$ enzyme, $\mathrm{NADPH}$ was used as the electron donor. Conversions of the substrate in the $\mathrm{H}_{2} \mathrm{O}_{2}$ cofactor system were included as controls 
no monooxygenase activity. The marginal residual activity of the two enzymes shown at $1200 \mathrm{U} \mathrm{mL}^{-1}$ catalase condition may represent some inevitable leakage of $\mathrm{H}_{2} \mathrm{O}_{2}$ to the $\mathrm{P} 450$ proteins, as even in the absence of putidaredoxin there was still meager activity detectable at this high catalase concentration (Additional file 1: Figure S5).

\section{Substrate specificity and chemoselectivity of CYP-Aa162 and CYP-Sm $46 \Delta 29$}

Members in the CYP152 peroxygenase family are capable of utilizing $\mathrm{H}_{2} \mathrm{O}_{2}$ as the sole electron and oxygen donor to carry out catalytic reactions [33]. Among those CYP152s that have been biochemically characterized so far, $\mathrm{OleT}_{\mathrm{JE}}$ catalyzes predominantly the decarboxylation of longchain fatty acids to give 1-alkenes as the main products and $\alpha$ - and $\beta$-hydroxy fatty acids as the side products [13]. Other CYP152 enzymes including $\mathrm{P}^{4} 50_{\mathrm{SP \alpha}}, \mathrm{P} 450_{\mathrm{BS} \beta}$, and CYP-MP catalyze primarily the hydroxylation of free fatty acids, introducing the hydroxyl group at varying carbon positions (i.e., $\alpha-, \beta-, \gamma^{-}, \delta$-, or $\varepsilon$-position) $[24,34$, $35,37]$. Here, in order to investigate the substrate specificity and chemoselectivity (decarboxylation vs hydroxylation) of the two new CYP152 enzymes, we set out to examine their catalytic reactions towards a range of different carbon chain length $\left(\mathrm{C}_{10}-\mathrm{C}_{20}\right)$ FFAs using $\mathrm{H}_{2} \mathrm{O}_{2}$ as the sole cofactor.

As a result, both enzymes exhibited quite similar substrate preference profiles with lauric acid $\left(\mathrm{C}_{12}\right)$ being the best substrate (Fig. 3). Its conversion ratios were $77.3 \pm 1.0$ and $83.5 \pm 3.4 \%$ by CYP-Aa162 and CYPSm $46 \Delta 29$, respectively. In addition, CYP-Sm $46 \Delta 29$ also converted myristic acid $\left(\mathrm{C}_{14}\right)$ efficiently $(74.5 \pm 3.5 \%)$. However, in terms of decarboxylation, CYP-Aa162 showed only marginal alkene production from its best substrate $\mathrm{C}_{12}(5.1 \pm 0.1 \%)$, whereas CYP-Sm $46 \Delta 29$ exhibited significantly higher percentage of alkene production.
The optimal substrates $\mathrm{C}_{12}$ and $\mathrm{C}_{14}$ FFAs reached the alkene production efficiency of $66.1 \pm 3.9$ and $57.4 \pm 3.6 \%$, respectively. Unlike previously reported for $\mathrm{OleT}_{\mathrm{IE}}$ by others [13, 21], CYP-Sm $46 \Delta 29$ favors more the mediumchain length fatty acids $\left(\mathrm{C}_{12}\right.$ or $\left.\mathrm{C}_{14}\right)$ rather than the long ones $\left(\mathrm{C}_{16}-\mathrm{C}_{20}\right)$. The decarboxylation activity of CYPSm46 29 (Fig. 3) and the ratio of decarboxylation over hydroxylation activities (Additional file 1: Figure S6) gradually reduced after $\mathrm{C}_{12}$ with the increase in substrate carbon chain length, and the hydroxyl FAs became the major products in the reactions with $\mathrm{C}_{18}$ or $\mathrm{C}_{20}$ as a substrate, indicating that different substrate binding modes are likely employed by this enzyme.

In consideration of the high sequence identity (64\%) and similar UV-visible absorption maxima between CYP-Aa162 and $\mathrm{P} 450_{\mathrm{BS} \beta}$, we compared their catalytic activities in parallel. As shown in Fig. 4, the two enzymes exhibited very similar substrate preference spectra and total fatty acid conversion efficiency. However, $\mathrm{P} 450_{\mathrm{BS} \beta}$ showed generally higher alkene production ratios compared with CYP-Aa162. The best alkene-producing substrate lauric acid $\left(\mathrm{C}_{12}\right)$ displayed a fivefold higher 1 -undecene production $(27.7 \pm 0.9 \%$ versus $5.1 \pm 0.1 \%)$. Nonetheless, substrate hydroxylation still represented the major chemistry of the two enzymes, which is not surprising since $\mathrm{P} 450_{\mathrm{BS} \beta}$ was initially identified as a $\mathrm{P} 450$ fatty acid hydroxylase [35]. The hydroxylation versus decarboxylation ratios of the two CYPs towards their preferred $\mathrm{C}_{10}-\mathrm{C}_{14}$ substrates were at least 2.5:1. Thus, we designated CYP-Aa162 as a $\mathrm{P} 450_{\mathrm{BS} \beta}$-like fatty acid hydroxylase rather than a $\mathrm{P} 450$ decarboxylase.

Furthermore, to comparatively investigate the detailed product distribution, the $\mathrm{C}_{14}$ substrate myristic acid was reacted with the four enzymes CYP-Aa162,

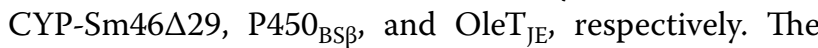
results (Table 1) revealed that CYP-Aa162 formed
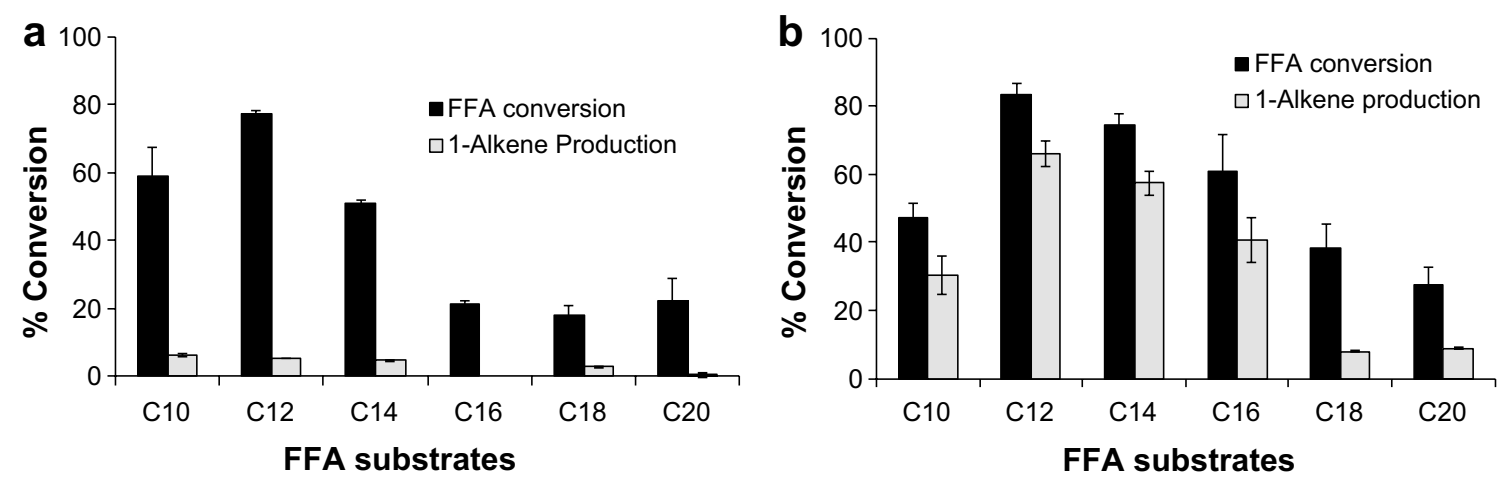

Fig. 3 Substrate preference and 1-alkene production profiles of CYP-Aa162 (a) and CYP-Sm46 29 (b). Substrate preference was determined by calculating the percentage conversion of each fatty acid substrate. The corresponding 1-alkene production represents the percentage of 1-alkene yield over the starting substrate. Results shown are mean \pm SD of duplicated experiments 


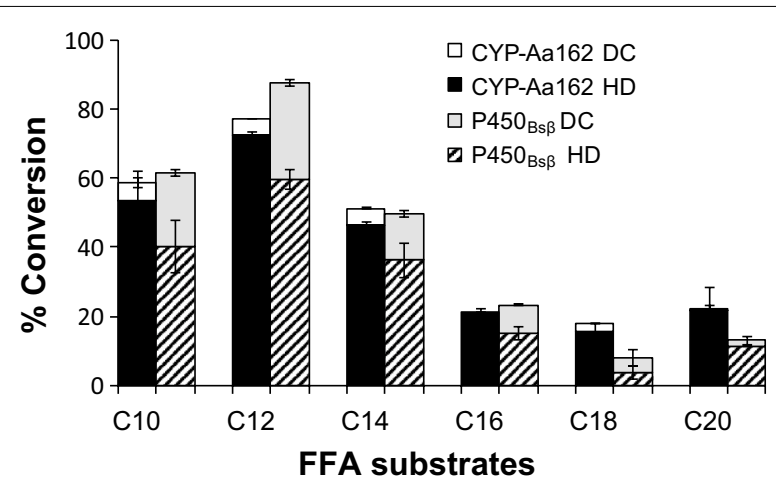

Fig. 4 Decarboxylation (DC) versus hydroxylation (HD) activities of CYP-Aa162 and P450 ${ }_{B S \beta}$. The hydroxylation activity was estimated by subtracting the alkene production from the total substrate conversion. This indirect but more convenient method was validated with $\mathrm{C}_{14}$ myristic acid substrate by direct measurement of its derivatized hydroxylation products. Results are shown as mean \pm SD of duplicated experiments

Table 1 GC-MS analysis of catalytic activities and product distribution profiles of the selected CYP152 peroxygenases towards myristic acid $\left(C_{14}\right)$

\begin{tabular}{|c|c|c|c|c|}
\hline \multirow[t]{2}{*}{ Enzymes } & \multirow[t]{2}{*}{ Conversion (\%) } & \multicolumn{3}{|c|}{ Product distribution (\%) } \\
\hline & & 1-tridecene & $\mathrm{a}-\mathrm{OH}-\mathrm{C}_{14}$ & $\beta-\mathrm{OH}-\mathrm{C}_{14}$ \\
\hline CYP-Aa162 & $60.1 \pm 2.1$ & $16.0 \pm 1.2$ & $78.9 \pm 1.4$ & $5.1 \pm 0.6$ \\
\hline$P 450_{B S \beta}$ & $62.8 \pm 5.0$ & $36.8 \pm 3.5$ & $30.0 \pm 4.2$ & $33.2 \pm 3.5$ \\
\hline CYP-Sm46 $\triangle 29$ & $73.2 \pm 8.9$ & $78.4 \pm 2.9$ & $0.4 \pm 0.1$ & $21.2 \pm 0.9$ \\
\hline $\mathrm{OleT}_{\mathrm{JE}}$ & $74.2 \pm 2.9$ & $91.8 \pm 5.9$ & $0.3 \pm 0.1$ & $7.9 \pm 1.5$ \\
\hline
\end{tabular}

predominantly $(78.9 \pm 1.4 \%)$ the $\alpha$-hydroxy myristic acid $\left(\alpha-\mathrm{OH}-\mathrm{C}_{14}\right)$, and $\mathrm{P} 450_{\mathrm{BS} \beta}$ exhibited approximately even distribution among the three products $\alpha-\mathrm{OH}-$ $\mathrm{C}_{14}, \beta-\mathrm{OH}-\mathrm{C}_{14}$, and 1-tridecene. In comparison, CYPSm46 29 and OleT $_{\mathrm{IE}}$ showed strong decarboxylation chemoselectivity. For these two enzymes, 1-tridecene was the major product, $\beta-\mathrm{OH}-\mathrm{C}_{14}$ the minor product, while $\alpha-\mathrm{OH}-\mathrm{C}_{14}$ only accounted for a negligible proportion of the total products. In all cases, no distal hydroxylated fatty acids beyond $\mathrm{C}_{\beta}$ position were detected, as opposed to the mixed regioselectivity found with the CYP-MP enzyme [24]. Together, these data strongly support the notion that CYP-Aa162 functions as a $\mathrm{P} 450_{\mathrm{BS} \beta}$-like fatty acid hydroxylase, while CYP-Sm $46 \Delta 29$ acts as an efficient $\mathrm{OleT}_{\mathrm{IE}}$-like decarboxylase, providing another enzyme to the unusual fatty acid oxidative decarboxylation reaction (Additional file 1: Figure S7).

\section{Site-directed mutagenesis of CYP-Aa162 and $\mathrm{P}^{4} 50_{\mathrm{BS} \beta}$ fatty acid hydroxylases}

The active-site sequence alignment of CYP-Aa162 and CYP-Sm46 429 with those of $\mathrm{P} 450_{\mathrm{BS} \beta}$ and $\mathrm{OleT}_{\mathrm{JE}}$ revealed two major residue differences (Additional file 1: Figure S8): the histidine and isoleucine residues in the FFA decarboxylases of $\mathrm{OleT}_{\mathrm{IE}}$ (H85 and I170) and CYPSm46 29 (H86 and I171) are replaced by a glutamine and a valine in CYP-Aa162 (Q85 and V170) and P450 ${ }_{\mathrm{BS} \beta}(\mathrm{Q} 85$ and V170), respectively. According to the crystal structure of OleT $_{\text {JE }}$ (PDB: 4L40) [18], H85 and I170 are positioned at the two sides of the substrate carboxyl group with the distance of 5.1 and $3.4 \AA$, respectively. Previously, Rude et al. [13] reported an improved decarboxylation activity ( $50 \%)$ of $\mathrm{P} 450_{\mathrm{BS} \beta} \mathrm{Q} 85 \mathrm{H}$ variant towards palmitic acid $\left(\mathrm{C}_{16}\right)$, suggesting an important role of this histidine residue in regulating the decarboxylation chemoselectivity of $\mathrm{OleT}_{\mathrm{JE}}$. Grant et al. [20] also proposed mechanisms in which $\mathrm{H} 85$ of $\mathrm{OleT}_{\mathrm{IE}}$ may act as a proton donor to facilitate the protonation of $\mathrm{OleT}_{\mathrm{IE}}$-Compound II intermediate $\left(\mathrm{Fe}^{4+}-\mathrm{OH}\right)$ generated from substrate $\mathrm{C}-\mathrm{H}$ abstraction and thereby to initiate substrate $\mathrm{C}-$ $\mathrm{C}_{\alpha}$ bond scission (i.e., decarboxylation). Moreover, our recent saturation mutagenesis analysis of $\mathrm{OleT}_{\mathrm{IE}}$ at $\mathrm{H} 85$ and I170 sites also confirmed the importance of these two amino acid residues for decarboxylation activity and substrate positioning based on the finding that all H85X (X denotes any natural amino acid) and I170X mutants exhibited abolished decarboxylation activity towards myristic acid [26].

Therefore, in view of the potential key roles of these two residues in regulating decarboxylation process and substrate positioning, we decided to substitute the corresponding amino acids in CYP-Aa162 and $\mathrm{P} 450_{\mathrm{Bs} \beta}$ with His and Ile, and created the double mutants Aa162/Q85H/ V170I and $\mathrm{P}^{4} 50_{\mathrm{Bs}} / \mathrm{Q} 85 \mathrm{H} / \mathrm{V} 170 \mathrm{I}$. Their in vitro activities towards a series of free fatty acid substrates $\left(\mathrm{C}_{10}-\mathrm{C}_{20}\right)$ were evaluated along with their corresponding wild types. As a result, the $\mathrm{P} 450_{\mathrm{Bs} \beta} / \mathrm{Q} 85 \mathrm{H} / \mathrm{V} 170 \mathrm{I}$ mutant exhibited a general increase in the total substrate conversion ratios compared with its wild type, while Aa162/Q85H/V170I showed variations of increase or decrease in conversion efficiency towards different carbon chain length substrates (Fig. 5c). However, both mutants displayed enhanced decarboxylation activity to the tested substrates to different extents (Fig. 5d). This increase was more prominent in the longer carbon chain length substrates such as $\mathrm{C}_{16}$ palmitic acid (Fig. 5b) than in the shorter carbon chain length substrates such as $\mathrm{C}_{12}$ lauric acid (Fig. 5a). For $\mathrm{C}_{12}$ substrate, a 1.1- and a 0.9-fold increase in 1-undecene production were observed with Aa162/Q85H/V170I and P450 ${ }_{\mathrm{Bs \beta}} /$ Q85H/V170I mutant, accounting for a 1.7- and a 1.2-fold increase in the ratio of decarboxylation over hydroxylation activity, respectively (Fig. 5a). For $\mathrm{C}_{16}$ substrate, the production of 1-pentadecene exhibited an increase from undetectable by the wild type CYP-Aa162 to $6.9 \%$ by its double mutant Aa162/Q85H/V170I, and an increase of 

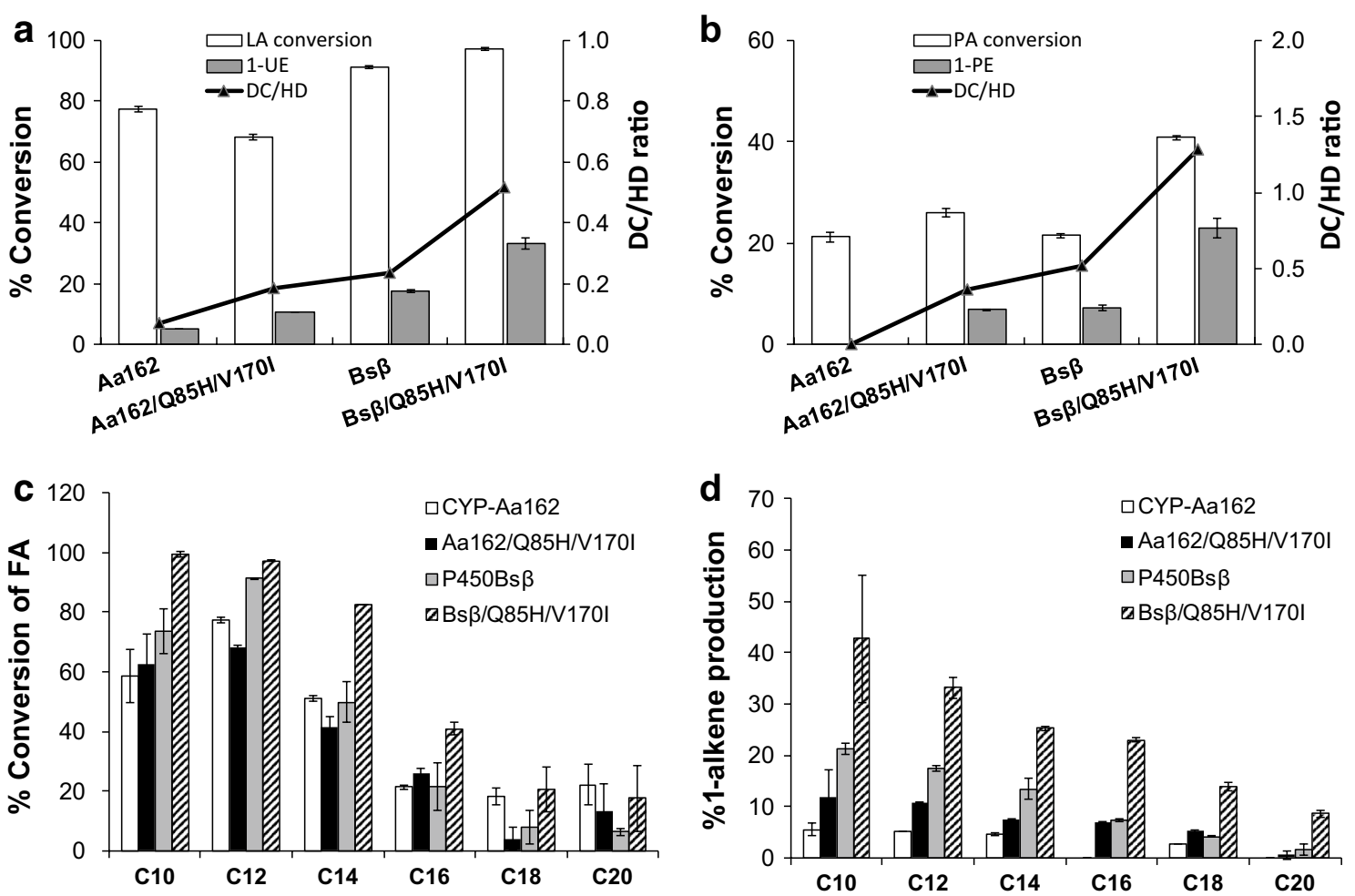

Fig. 5 Fatty acid conversion by the Aa162/Q85H/V170I and $\mathrm{P} 450_{\mathrm{BS} \beta} / \mathrm{Q} 85 \mathrm{H} / \mathrm{N} 170 \mathrm{l}$ mutants compared to their corresponding wild-type enzymes. The hydroxylation (HD) activity was deduced by subtracting the 1-alkene production (corresponding to DC activity) from the total substrate conversion. a Lauric acid (LA) conversion and 1-undecene (1-UE) production; b palmitic acid (PA) conversion and 1-pentadecene (1-PE) production; c conversion ratios of different carbon chain length fatty acids $\left(C_{10}-C_{20}\right)$ and $\mathbf{d}$ their corresponding 1-alkene production by the indicated enzymes. Results are presented as mean \pm SD of duplicated experiments

2.1-fold by the $\mathrm{P} 450_{\mathrm{Bs} \beta} / \mathrm{Q} 85 \mathrm{H} / \mathrm{V} 170 \mathrm{I}$ mutant when compared with its wild type $\mathrm{P} 450_{\mathrm{Bs} \beta}$. The latter increase led to a high decarboxylation versus hydroxylation ratio of around 1.3 in the $\mathrm{P} 450_{\mathrm{Bs} \beta} / \mathrm{Q} 85 \mathrm{H} / \mathrm{V} 170 \mathrm{I}$ mutant, making the 1-alkene the major product. Together, these results demonstrate the important role of the active-site histidine and isoleucine in regulating fatty acid decarboxylation activity of the CYP152 peroxygenases.

\section{Steady-state kinetics of CYP-Aa162 and CYP-Sm $46 \Delta 29$}

To better understand the catalytic properties of CYPAa162 fatty acid hydroxylase and CYP-Sm $46 \Delta 29$ fatty acid decarboxylase, we determined their steady-state kinetic parameters (Table 2) towards their optimal substrates $\mathrm{C}_{12}$ and/or $\mathrm{C}_{14}$ fatty acids. Since CYP-Aa162 mainly catalyzes the hydroxylation of fatty acids, trace amounts of alkene products were undetectable at the beginning of the reaction when initial rates were determined. Therefore, its kinetic constants were derived from the rates of substrate consumption. For CYPSm46 29 , the kinetic constants were specifically determined by 1 -alkene formation rates due to its much higher decarboxylation activity. Interestingly, it was revealed that the kinetic data of both CYP-Aa162 and CYP-Sm46 29 towards $\mathrm{C}_{12}$ substrate fit well to a sigmoidal Hill equation with a Hill coefficient value around 2 (Table 2; Additional file 1: Figure S9A, B). This may suggest that the substrate binding pocket of the two P450 enzymes could accommodate more than one $\mathrm{C}_{12}$ molecules and that the binding of one $\mathrm{C}_{12}$ molecule could facilitate the binding of the other to the same P450 enzyme, particularly at low to medium substrate concentrations $(10-80 \mu \mathrm{M})$. Notably, the kinetic data of CYP-Sm $46 \Delta 29$ towards $C_{14}$ substrate exhibited apparent and substantial substrate inhibition (Additional file 1: Figure S9C). When the substrate concentration was in excess of $60 \mu \mathrm{M}$, the rate of 1-tridecene formation declined dramatically, but was not completely abolished even at a high concentration of $300 \mu \mathrm{M}$. Rather, it flattened off to a low activity, indicating an incomplete inhibition. Estimation of the kinetic parameters for this substrate was therefore deduced from the truncated dataset using Michaelis-Menten equation after removal of the inhibited rates at high substrate concentrations [48]. The apparent $k_{\text {cat }}$ value of $62.5 \pm 4.5 \mathrm{~min}^{-1}$ is comparable 
Table 2 Kinetic parameters of FFA conversion catalyzed by CYP-Aa 162 and CYP-Sm $46 \Delta 29$

\begin{tabular}{|c|c|c|c|c|c|c|c|}
\hline \multirow[t]{2}{*}{ Enzymes } & \multicolumn{4}{|l|}{$C_{12}^{a}$} & \multicolumn{3}{|l|}{$C_{14}^{b}$} \\
\hline & $k_{\text {cat }}\left(\min ^{-1}\right)$ & $K_{H}(\mathrm{uM})$ & $K_{\text {cat }} / K_{H}\left(\mathrm{uM}^{-1} \mathrm{~min}^{-1}\right)$ & Hill coefficient $(n)$ & $k_{\text {cat }}\left(\min ^{-1}\right)$ & $K_{m}(\mathrm{uM})$ & $K_{\text {cat }} / K_{m}\left(\mathrm{uM}^{-1} \mathrm{~min}^{-1}\right)$ \\
\hline CYP-Aa162 & $46.1 \pm 17.1$ & $93.1 \pm 37.7$ & 0.5 & $2.1 \pm 0.8$ & nd & nd & nd \\
\hline CYP-Sm46 $\triangle 29^{d}$ & $24.5 \pm 6.3$ & $58.4 \pm 19.0$ & 0.4 & $2.2 \pm 1.0$ & $62.5 \pm 4.5$ & $41.3 \pm 5.1$ & 1.5 \\
\hline \\
\hline \multicolumn{8}{|c|}{ a Data were fitted to Hill equation $\left(v=V_{\max }[S]^{n} /\left(K_{H}^{n}+[S]^{n}\right), n\right.$ Hill coefficient $)$} \\
\hline \multicolumn{8}{|c|}{$\begin{array}{l}\text { b Substantial substrate inhibition was observed with this substrate. Data shown here were derived from Michaelis-Menten equation after omitting the inhibited rates } \\
\text { at high substrate concentrations }\end{array}$} \\
\hline \multicolumn{8}{|c|}{ c Initial rates were measured by the amount of substrate consumption per $\mu \mathrm{M}$ enzyme per min } \\
\hline
\end{tabular}

to that of $\mathrm{OleT}_{\mathrm{JE}}$ towards $\mathrm{C}_{14}$ substrate $\left(71.0 \pm 8.4 \mathrm{~min}^{-1}\right)$ [26]. Collectively, these data imply that, to different carbon chain length FFA substrates, the decarboxylase CYP-Sm $46 \Delta 29$ could present distinct binding modes and therefore display different kinetic behaviors.

\section{Discussion}

In this study, we successfully expressed, purified, and biochemically characterized two new CYP152 peroxygenase family members, CYP-Aa162 and CYP-Sm $46 \Delta 29$, that are capable of decarboxylating straight-chain saturated fatty acids to yield 1-alkenes to different extents. Previously, Chen et al. [49] compared the in vivo alkene production by expressing a His-tagged CYP-Sm46 (there called OleT $_{\mathrm{SM}}$, GenBank Accession Number: WP_009381667, an identical sequence to EKU50422, 453 amino acids) in $S$. cerevisiae, and only observed trace amounts of oddnumbered carbon chain alkenes $\left(\mathrm{C}_{13}, \mathrm{C}_{15}\right.$, and $\left.\mathrm{C}_{17}\right)$ from a 48-h culture of the recombinant yeast cells (total alkene titer $1.4 \mu \mathrm{g} \mathrm{L}^{-1}$, 40 times lower than that of $\mathrm{OleT}_{\mathrm{IE}}$ $54.5 \mu \mathrm{g} \mathrm{L}{ }^{-1}$ ). In that study, a 'full-length' version of CYPSm46 was used. No protein expression data were shown, nor was enzymatic characterization performed. Here, our experiment in E. coli proved very poor or no soluble expression of the 'full-length' version of CYP-Sm46. Translation in bacteria is most commonly initiated at an AUG start codon, which encodes for a methionine. However, in some species, the start codon can be GUG, which within the open reading frame (ORF) would encode for a valine. Staphylococcus aureus has been documented to use GUG as an alternative start codon [50]. The use of alternative initiation codons can influence translation efficiency, while incorrect initiation could lead to misfolded and therefore inactive proteins. The initial amino acid sequence of CYP-Sm46 (EKU50422) was most likely mistakenly derived from the usual AUG start codon as it happens to follow a putative Shine-Dalgarno sequence (AGGATG), which may explain why we did not observe decent expression with the original EKU50422 sequence. The later version of the amino acid sequence (CYP-Sm46 229 ) adopted GUG as its start codon (WP_039990689), and a possible Shine-Dalgarno site of $5^{\prime}$-TGGGGG-3' ${ }^{\prime}$ was found 7 base upstream of the putative GUG start codon in the mRNA sequence (Additional file 2). The RBS calculator 2.0 (http://www.denovodna. $\mathrm{com} /$ software/forward) analysis of the CYP-Sm46 mRNA sequence showed that the GUG has a fivefold higher translation rate (3.3-fold lower total initiation energy $\left.\Delta \mathrm{G}_{\text {Total }}\right)$ than that of the upstream AUG start codon. In addition, McLaughlin et al. [51] reported the identification of a very strong Shine-Dalgarno complementarity containing five G-C base pairs in the Staphylococcus aureus $\beta$-lactamase gene. This strong mRNA-16S rRNA binding was proposed to reduce dependence on other initiation factors in the Gram-positive bacteria such as Bacillus and Staphylococcus. Furthermore, analysis of mRNA sequences of cytochrome P450 family proteins from other Staphylococcus species such as S. agnetis (GenBank: JPRT01000001.1) and S. pseudintermedius (GenBank: CP002439.1) also revealed a similar pattern of the strong 5-6 G-C pairs of Shine-Dalgarno complementarity preceding a GUG start codon. Taken together, we reason that CYP-Sm $46 \Delta 29$ is most likely to be the native functional form of the protein.

P420 species was generally thought to be an inactive form of cytochrome P450 enzymes [52-54]. Formation of this 'inactive' P420 was suggested to involve the protonation of the native cysteine thiolate to a neutral thiol heme ligand [44], the recruitment of a histidine to replace the native cysteinate ligand [45], or other unknown reasons. Either way leads to the failure of forming the thiolate-ligated $\mathrm{Fe}^{2+}$ species or to a distorted/ weakened heme-thiolate bond, thus underlying the $\mathrm{P} 450 \rightarrow \mathrm{P} 420$ transition [45]. Most P420 studies were performed with the $\mathrm{P} 450_{\mathrm{BM}}[52,54]$ or $\mathrm{P} 450_{\text {cam }}[45,53]$ monooxygenases. These enzymes employ redox partner system to transfer electrons from $\mathrm{NAD}(\mathrm{P}) \mathrm{H}$ and activate $\mathrm{O}_{2}$ as the oxidant, whose catalytic activity depends 
on the formation of a specific thiolate bond between the heme iron and the absolutely conserved cysteine residue in order to afford an active conformation state [33]. P450 peroxygenases, on the other hand, unlike those monooxygenases, utilize peroxide (such as $\mathrm{H}_{2} \mathrm{O}_{2}$ ) to directly convert the heme iron of enzymes to a reactive ferric-hydroperoxy complex $\left(\mathrm{Fe}^{3+}-\mathrm{OOH}\right)$ via the peroxide shunt pathway [33, 36], therefore bypassing the oxygen activation chemistry and the necessity of forming the thiolate-ligated ferrous-heme species. Whether the failure of observing a P450 species in CYP-Sm46 229 is due to the instability of the thiolate-ligated $\mathrm{P} 450$ species that quickly reverts to a P420 form as with EpoK [43], or an alternative proximal ligand-coordinated species as in $\mathrm{P}^{4} 20_{\text {cam }}$ [45], $\mathrm{P} 450$ enzymes that undergo peroxide shunt pathway are insensitive to the nature of the proximal ligand as they do not require electron transfer to the heme iron. Peroxide activation can be achieved equally well with, for example, the histidine-ligated hemoproteins [55]. Therefore, as opposed to the generally regarded 'inactive' cytochrome $\mathrm{P} 420$ species in the $\mathrm{P} 450$ monooxygenases, the peroxygenase ' $\mathrm{P} 420$ ' enzymes can be active. We reason that this difference may explain why we observed no thiolate-ligated $\mathrm{P} 450$ ferrous-heme species but a functional CYP-Sm $46 \Delta 29$. Indeed, we observed efficient catalytic activity of CYP-Sm $46 \Delta 29$ in the $\mathrm{H}_{2} \mathrm{O}_{2}$ system, but not in the $\mathrm{H}_{2} \mathrm{O}_{2}$-depleted $\mathrm{O}_{2}$ /redox proteins/ NADH system (Fig. 2b). A minor increase in the activities of CYP-Aa162 and CYP-Sm46 29 was observed in the catalase-absent redox partner-supported reaction system (Fig. 2b). This increase may reflect the beneficial effect of slow-releasing $\mathrm{H}_{2} \mathrm{O}_{2}$ from NADH decoupling on the catalytic activity, compared with the batch-added $\mathrm{H}_{2} \mathrm{O}_{2}$ [24] . However, considering the unique spectroscopic features of the CYP-Sm $46 \Delta 29$, further structural and mechanistic studies are certainly required to gain more detailed understanding of the active-site coordination environment of this enzyme and its catalytic mechanism.

The strict carbon chain length dependence of the decarboxylative activity of CYP-Sm46 229 is consistent with other identified decarboxylative activities in $\mathrm{OleT}_{\mathrm{JE}}[13$, 16, 22], $\mathrm{P} 40_{\mathrm{BS} \beta}$ [37], and CYP-MP [24], which further emphasizes the importance of substrate identity in controlling the hydroxylation/decarboxylation bifurcation. This substrate identity-dependent chemistry was also manifested in a recent study of $\mathrm{OleT}_{\mathrm{IE}}$ where only trace amounts $(<1-2 \%)$ of undesired hydroxyl side products were generated when aromatic carboxylic acids were used as substrates [29]. Our finding that low alkene production in CYP-Aa162 is accompanied with a high percentage of $\alpha$-hydroxyl product is also consistent with the notion that $\mathrm{C}_{\beta}-\mathrm{H}$ rather than $\mathrm{C}_{\alpha}-\mathrm{H}$ abstraction is a prerequisite for initiation of fatty acid decarboxylation pathway.
However, this could not be the sole determining factor as CYP-MP produced predominantly the $\beta-\mathrm{OH}$ fatty acid but only a meager amount of alkenes [24]. For OleT $\mathrm{T}_{\mathrm{E}}$, it was proposed that His85 could facilitate the decarboxylation pathway through providing proton to the $\mathrm{Fe}^{4+}-\mathrm{OH}$ (compound II) intermediate to restore a water-bound $\mathrm{Fe}^{3+}-\mathrm{OH}_{2}$ species $[18,20]$. An active-site histidine may also help with the precise substrate positioning required for the decarboxylation pathway [26]. In the absence of an active-site histidine, $\mathrm{OH}$ rebound would be the prevalent pathway, leading to accumulated hydroxyl fatty acids, such as the case with CYP-MP [24], P450 Bsß [13], and CYP-Aa162 in this study. Our site-directed mutagenesis analysis of CYP-Aa162 and $\mathrm{P} 450_{\mathrm{Bs} \beta}$ confirmed the importance of this residue in regulating decarboxylation selectivity. However, the introduction of this histidine residue did not fully reverse the chemoselectivity of either CYPMP [24] or CYP-Aa162 (Fig. 5), albeit an increase in the decarboxylation activity, hydroxylation was still the major chemistry of CYP-Aa162/Q85H/V170I. This implies that more structural and electronic requirements need to be satisfied to be a fatty acid decarboxylase.

Makris and coworkers [19, 20] recently confirmed that $\mathrm{OleT}_{\mathrm{JE}}$ catalysis is initiated by the formation of an iron(IV)-oxo cation radical (compound I). The fatty acid decarboxylation bifurcation is believed to begin with a regio-specific $\mathrm{C}_{\beta}-\mathrm{H}$ abstraction followed by a singleelectron transfer from either a substrate carboxylate group or an additional electron from the $\mathrm{C}_{\beta}$ position to the incipient compound II, resulting in the generation of a substrate diradical or a substrate carbocation, respectively, to fulfill $\mathrm{C}-\mathrm{C}_{\alpha}$ bond scission and give rise to the terminal alkene products. Our data here together with others $[13,18-20,23,24]$ suggest that substrate $C_{\beta}-H$ abstraction, chain length-dependent precise positioning at the active site, relative intrinsic stability of the enzyme/ $\mathrm{Fe}^{4+}-\mathrm{OH}$ intermediate (compound II), and the competition between $\mathrm{OH}$ rebound and abstraction of an additional substrate electron by compound II are among the decarboxylation bifurcation determinants to ensure a desaturation reaction. Given that site-directed mutagenesis did not fully boost the decarboxylation activity of CYP-Aa162, alternative approaches such as directed evolution may represent an attractive method for engineering improved alkene formation activity towards, especially, particular chain length substrates, and for thorough understanding of the enzyme structure-function relationship.

A majority of P450 catalyses follow simple Michaelis-Menten kinetics based on a single active site for the substrate-enzyme interaction [56]. However, there are growing cases that non-Michaelis-Menten kinetics were observed for some P450 reactions [48, 57-59]. In the 
latter cases, the non-classical kinetics apparently results from allosteric effects that commonly lead to a sigmoidal velocity curve. The Hill equation can be used to indicate cooperative kinetics. Indeed, several studies have found that some P450s are able to fit into its active site with large molecules such as cyclosporine [60] or two substrates at once [57]. The two substrates can be the same or different molecules allowing the homotropic or heterotropic cooperative kinetics, respectively. Other examples of cooperative catalysis were found with $\mathrm{P}^{4} 50_{\mathrm{SP} \alpha}[61,62]$ and $\mathrm{P} 450_{\mathrm{BS} \beta}[62,63]$ where short-chain length fatty acids (such as heptanoic acid or hexanoic acid) could act as 'decoy molecules' to facilitate the binding of non-natural substrates (such as styrene) and their oxidation by these P450 peroxygenases. In this study, cooperative binding of $\mathrm{C}_{12}$ lauric acid substrate to CYP-Aa162 and CYPSm46 29 enzymes was observed with a Hill coefficient of $\sim 2$ (Table 1). The smaller $k_{c a t}$ and $k_{c a t} / K_{m}$ values of CYPSm46 $\Delta 29$ towards $C_{12}$ lauric acid $\left(24.5 \pm 6.3 \mathrm{~min}^{-1}\right.$ and $\left.0.4 \mu \mathrm{M}^{-1} \mathrm{~min}^{-1}\right)$ than those towards $\mathrm{C}_{14}$ myristic acid $\left(62.5 \pm 4.5 \mathrm{~min}^{-1}\right.$ and $\left.1.5 \mu \mathrm{M}^{-1} \mathrm{~min}^{-1}\right)$ may appear to be contradictory to the qualitative substrate specificity results (Fig. 2) which demonstrated higher conversion efficiency of $\mathrm{C}_{12}$ over $\mathrm{C}_{14}$ by this enzyme. We reason that this inconsistency may stem from the substrate inhibition of this enzyme by the high substrate concentration of $\mathrm{C}_{14}$ $(200 \mu \mathrm{M}$ substrate was used for the substrate specificity profiling assay).

\section{Conclusions}

In this study, we have characterized two new CYP152 peroxygenases with regard to their spectroscopic characteristics, substrate specificity, decarboxylation/ hydroxylation chemoselectivity, and kinetics. Our data demonstrate that CYP-Sm $46 \Delta 29$ works as an efficient $\mathrm{OleT}_{\mathrm{JE}}$-like fatty acid decarboxylase, while CYP-Aa162 acts as a $\mathrm{P} 450_{\mathrm{BS} \beta}$-like fatty acid hydroxylase with marginal decarboxylation chemoselectivity. Furthermore, CYP-Sm $46 \Delta 29$ was found to be catalytically active without forming a stable P450 species. Its decarboxylation activity exhibited strict carbon chain length dependence, suggesting the requirement of precise active-site positioning of substrates to be decarboxylated. Moreover, towards different carbon chain length fatty acids, CYP-Sm $46 \Delta 29$ undertook different kinetic behaviors (cooperative or substrate inhibition), further stressing the importance and impact of elaborate coordination of substrate within the substrate binding pocket. Taken together, our findings could provide more opportunities for further understanding the unique catalytic mechanism employed by CYP152 fatty acid decarboxylases and also serve as a guide for future bioengineering of the enzymes for improved alkene-producing activity of different carbon chain length substrates.

\section{Methods \\ Materials}

Fatty acid substrates, terminal alkene authentic standards, $\alpha$-hydroxy myristic acid, $\beta$-hydroxy myristic acid, and $N, O-$ bis(trimethylsilyl)trifluoroacetamide (BSTFA) with $1 \%$ trimethylchlorosilane were purchased from TCI (Shanghai, China). Catalase from bovine liver (\# C1345) was purchased from Sigma-Aldrich (St. Louis, MO, USA). One unit is defined, as described in the manufacturer's instruction, to decompose $1.0 \mu \mathrm{mol}$ of $\mathrm{H}_{2} \mathrm{O}_{2} \mathrm{~min}^{-1}$ at $\mathrm{pH} 7.0$ at $25{ }^{\circ} \mathrm{C}$, while the $\mathrm{H}_{2} \mathrm{O}_{2}$ concentration falls from 10.3 to $9.2 \mathrm{mM}$, measured by the rate of decrease of $\mathrm{A}_{240}$. $\mathrm{NADH}$ and antibiotics were obtained from Solarbio (Beijing, China). Other chemicals were purchased from Ameresco (Solon, OH, USA) or Sigma-Aldrich (St. Louis, MO, USA). Molecular cloning kits, such as High Purity Plasmid Miniprep Kit and Wizard SV Gel and PCR Clean-up System, were purchased from TSINGKE Biotech (Beijing, China) and Promega (Madison, WI, USA), respectively. Oligonucleotides and codon-optimized genes were synthesized by Genewiz (Suzhou, China). The Pfu DNA polymerases and all restriction endonucleases were obtained from Takara (Dalian, China). Ni-NTA resin used for protein purification was purchased from Qiagen (Valencia, CA, USA). The FlexiRun $^{\mathrm{TM}}$ pre-mixed gel solution for SDS-PAGE was obtained from MDBio, Amicon Ultra centrifugal filters from Millipore (Billerica, MA, USA), and PD-10 desalting columns from GE Healthcare (Piscataway, NJ, USA).

\section{Molecular cloning}

The gene sequences encoding CYP-Aa162 from Alicyclobacillus acidocaldarius LAA1 (CYP152A8, GenBank Accession Number: WP_008340313) and CYP-Sm46 from Staphylococcus massiliensis strain S46 (CYP152L2, GenBank Accession Number: EKU50422) were, respectively, codon-optimized and synthesized by Genewiz (Suzhou, China), and cloned into the expression vector pET28b between NdeI/XhoI restriction sites with a hexahistidine tag at the $N$ terminus for expression in $E$. coli BL21 (DE3). The truncated CYP-Sm46 29 gene (WP_039990689) was PCR-amplified from the initial construct of pET28b-CYPSm46 using Pfu DNA polymerase and then subcloned into pET28b vector using the same restriction sites as above. The generation of double mutant gene constructs of Aa162/Q85H/V170I and $\mathrm{P} 450_{\mathrm{BS} \beta} / \mathrm{Q} 85 \mathrm{H} / \mathrm{V} 170 \mathrm{I}$ was achieved by site-directed mutagenesis via overlap extension PCR [64]. The sequences of primers used in this study are listed in Additional file 3: Table S1. All plasmid constructs were confirmed by DNA sequencing at Sangon 
Biotech (Shanghai, China). Upon sequence verification, plasmids were used to transform E. coli BL21 (DE3) for protein expression.

\section{Heterologous expression and purification}

The E. coli BL21 (DE3) cells transformed with pET28bCYP-Sm46429, pET28b-CYP-Aa162, or the Q85H/ V170I double mutant constructs were grown overnight at $37{ }^{\circ} \mathrm{C}$ with shaking at $220 \mathrm{rpm}$ in LB medium containing $50 \mu \mathrm{g} \mathrm{mL}^{-1}$ kanamycin. The overnight culture was used as a seed culture to inoculate (1:100 dilution) $1-3 \mathrm{~L}$ of modified terrific broth containing $4 \%$ glycerol, $1 \mathrm{mM}$ thiamine, trace metals [16], and the corresponding antibiotics. Cells were then grown at $37^{\circ} \mathrm{C}$ for $3-4 \mathrm{~h}$ until the optical density at $600 \mathrm{~nm}\left(\mathrm{OD}_{600}\right)$ reached $\sim 0.6$, at which point $\delta$-aminolevulinic acid ( $0.5 \mathrm{mM}$ final concentration) was supplemented and the expression of CYP-Sm $46 \Delta 29$ was induced by the addition of $0.2 \mathrm{mM}$ isopropyl- $\beta$ D-thiogalactopyranoside (IPTG). Cells were further cultured for $24 \mathrm{~h}$ at $18{ }^{\circ} \mathrm{C}$ before being harvested by centrifugation at $6000 \mathrm{rpm}, 4{ }^{\circ} \mathrm{C}$. The cell pellet was frozen at $-80{ }^{\circ} \mathrm{C}$ until required.

Purification of the His-tagged protein was carried out as described by Liu et al. [16] with minor modifications. All protein purification steps were performed at $4{ }^{\circ} \mathrm{C}$. Specifically, the cell pellets were thawed and resuspended in $40 \mathrm{~mL}$ lysis buffer $\left(50 \mathrm{mM} \mathrm{NaH}{ }_{2} \mathrm{PO}_{4}, 300 \mathrm{mM} \mathrm{NaCl}\right.$, $10 \%$ glycerol, and $10 \mathrm{mM}$ imidazole, $\mathrm{pH}$ 8.0) through vortexing. After cell disruption by ultrasonication, the cell lysate was centrifuged at $12,000 \times g$ for $30 \mathrm{~min}$ to remove cellular debris. To the clarified cell lysate, $1 \mathrm{~mL}$ of Ni-NTA resin was added and gently mixed at $4{ }^{\circ} \mathrm{C}$ for $1 \mathrm{~h}$. The slurry was then loaded onto an empty column and washed with approximately $100 \mathrm{~mL}$ of wash buffer (50 $\mathrm{mM} \mathrm{NaH} \mathrm{PO}_{4}, 300 \mathrm{mM} \mathrm{NaCl}, 10 \%$ glycerol, and $20 \mathrm{mM}$ imidazole, $\mathrm{pH}$ 8.0) until no proteins were detectable in flowthrough. The bound target proteins were eluted with elution buffer $\left(50 \mathrm{mM} \mathrm{NaH} \mathrm{PO}_{4}, 300 \mathrm{mM}\right.$ $\mathrm{NaCl}, 10 \%$ glycerol, and $250 \mathrm{mM}$ imidazole, $\mathrm{pH}$ 8.0). The eluates were pooled and concentrated with an Amicon Ultra centrifugal filter ( $30 \mathrm{kDa}$ cutoff). Imidazole contained in the protein eluates was removed by ultrafiltration and buffer exchange on a PD-10 column into storage buffer $\left(50 \mathrm{mM} \mathrm{NaH} \mathrm{PO}_{4}, 300 \mathrm{mM} \mathrm{NaCl}, 10 \%\right.$ glycerol, $\mathrm{pH}$ 7.4). The final purified protein was flash-frozen with liquid nitrogen and stored at $-80{ }^{\circ} \mathrm{C}$ for later use.

\section{UV-visible spectroscopic characterization of CYPs}

Analysis of the UV-visible spectroscopic properties of the His-tagged CYP-Aa162 and CYP-Sm46 229 was performed on a Cary 60 UV-visible spectrophotometer (Varian, UK). For preparation of the dithionite-reduced ferrous$\mathrm{CO}$ complex of each enzyme, carbon monoxide gas was slowly bubbled into a solution of purified ferric enzyme $(\sim 4-7 \mu \mathrm{M})$ in $50 \mathrm{mM} \mathrm{NaH}_{2} \mathrm{PO}_{4}, 300 \mathrm{mM} \mathrm{NaCl}, 10 \%$ glycerol, $\mathrm{pH} 7.4$, immediately followed by sufficient reduction of the protein with sodium dithionite $(1-3 \mathrm{mg})$ [65]. The optical absorption spectra of the ferric and ferrous-CO forms of each enzyme were recorded, respectively, before and after the addition of sodium dithionite. The CO-bound reduced difference spectrum was obtained according to the previous report [66]. In order to record the spectra in the redox partners/NAD(P)H/CO system, lauric acid $(\sim 0.7 \mathrm{mM})$ was pre-incubated with the cytochrome proteins for $5 \mathrm{~min}$ at $28{ }^{\circ} \mathrm{C}$ before the absorbance of ferric forms was recorded. Then, to the substrate-bound protein solution was added the CamAB/NADH (for CYP-Aa162 and CYP-Sm46 29 ) or NADPH (for the self-sufficient $\left.\mathrm{P}^{4} 50_{\mathrm{BM} 3}\right)$ cofactors to initiate a flavin-to-heme electron transfer. Spectra of the CO-bound $\mathrm{NAD}(\mathrm{P}) \mathrm{H}$-reduced forms of the P450 enzymes were subsequently recorded. The protein concentration was determined by the extinction coefficient of $\varepsilon_{422 \mathrm{~nm}}=104 \mathrm{mM}^{-1} \mathrm{~cm}^{-1}$ as determined using the pyridine hemochromogen method [67]. The typical methodology for determination of the P450 functional concentration using $\varepsilon_{450-490 \mathrm{~nm}}$ [66] was abandoned due to lack of the P450 content in the CYP-Sm46 29 spectra.

\section{In vitro enzymatic assay}

Typical assays containing $1.5 \mu \mathrm{M}$ of each CYP enzyme (CYP-Sm46 29 or CYP-Aa162 or their mutant), $200 \mu \mathrm{M}$ fatty acid substrate (one of the $\mathrm{C}_{10}-\mathrm{C}_{20}$ FFAs prepared from a $20 \mathrm{mM}$ stock solution in DMSO), and $220 \mu \mathrm{M}$ $\mathrm{H}_{2} \mathrm{O}_{2}$ in $200 \mu \mathrm{L}$ of storage buffer were carried out at $28^{\circ} \mathrm{C}$ for $2 \mathrm{~h}$. Reactions were quenched by the addition of $20 \mu \mathrm{L}$ of $10 \mathrm{M} \mathrm{HCl}$. Heptadecanoic acid was then added as the internal standard, and the mixture was extracted by $200 \mu \mathrm{L}$ ethyl acetate. Following extraction, the organic phase was collected and analyzed by gas chromatography (GC) as described below.

For detection of the volatile $\mathrm{C}_{9}$ nonene product generated from $\mathrm{C}_{10}$ fatty acid decarboxylation, $500 \mu \mathrm{L}$ of the reaction system containing $200 \mu \mathrm{M} \mathrm{C}_{10}$ fatty acid substrate, $220 \mu \mathrm{M} \mathrm{H}_{2} \mathrm{O}_{2}, 2.0 \mu \mathrm{M}$ of enzyme, and $200 \mu \mathrm{M} \mathrm{C}_{7}$ 1-heptene as the internal standard in a $1.5 \mathrm{~mL}$ polytetrafluorethylene (PTFE) septum-sealed glass bottles was incubated at $28^{\circ} \mathrm{C}$ for $2 \mathrm{~h}$ with shaking at $300 \mathrm{rpm}$. The reactions were then placed on ice and subjected to headspace sampling using a gas-tight Hamilton syringe for GC-MS analysis as described below. The standard curve of nonene was obtained by incubating different concentrations of the authentic nonene standard under the same condition as the reactions without enzyme followed by the same GC-MS analysis. After headspace sampling, the reactions were immediately mixed with ethyl acetate and the internal standard heptadecanoic acid and extracted 
as described above for the analysis of the remaining $\mathrm{C}_{10}$ substrates. With every tested substrate $\left(\mathrm{C}_{10}-\mathrm{C}_{20}\right.$ FFAs), a reaction without $\mathrm{H}_{2} \mathrm{O}_{2}$ was used as the control for the initial substrate concentration.

\section{Steady-state kinetic analysis}

To determine the P450 kinetic parameters, $0.1-0.5 \mathrm{nM}$ of enzyme was incubated with varying concentrations of substrate $\left(\mathrm{C}_{12}\right.$ or $\left.\mathrm{C}_{14}\right)$ at $28^{\circ} \mathrm{C}$ in a $1 \mathrm{~mL}$ reaction system (50 mM NaH $\mathrm{PO}_{4}, 300 \mathrm{mM} \mathrm{NaCl}, \mathrm{pH} 7.4,10 \%$ glycerol) supplemented with an excess amount of $\mathrm{H}_{2} \mathrm{O}_{2}$ as a cofactor. Aliquots $(200 \mu \mathrm{L})$ of reactions were removed and quenched at specific time points (usually at $0,1,3$, and $5 \mathrm{~min}$ ) by adding $1 / 10$ volume of $1 \mathrm{M} \mathrm{HCl}$. Heptadecanoic acid was then added as the internal standard. Subsequent sample preparation was performed (as above) for GC analysis (as below). Initial rates were calculated from either the substrate consumption for CYP-Aa162 or the 1-alkene production for CYP-Sm46 29 . Kinetic analyses were performed using OriginPro 8.0 program.

\section{Gas chromatography (GC) and GC-MS}

The GC analytical method for hydrocarbon and fatty acid samples was adapted from Guan et al. [68]. The analyses were performed on an Agilent $7890 \mathrm{~B}$ gas chromatograph equipped with a capillary column HPINNOWAX (Agilent Technologies, Santa Clara, CA, USA; cross-linked polyethylene glycerol, i.d. $0.25 \mu \mathrm{m}$ film thickness, $30 \mathrm{~m}$ by $0.25 \mathrm{~mm}$ ). The helium flow rate was set to $1 \mathrm{~mL}$ per min. The oven temperature was controlled initially at $40{ }^{\circ} \mathrm{C}$ for $4 \mathrm{~min}$, then increased at the rate of $10{ }^{\circ} \mathrm{C} \min ^{-1}$ to $280{ }^{\circ} \mathrm{C}$, and held for $5 \mathrm{~min}$. The injecting temperature was set to $280{ }^{\circ} \mathrm{C}$ with the injection volume of $1 \mu \mathrm{L}$ under splitless injection conditions. The retention times and signal intensity of fatty acids and alkenes were determined by analyzing and comparing with known authentic fatty acids $\left(\mathrm{C}_{10}-\mathrm{C}_{20}\right), 1$-alkenes $\left(\mathrm{C}_{11}-\mathrm{C}_{19}\right)$, and 1-heptadecanoic acid standards [16]. For GC-MS, the gas chromatography equipment was coupled to an Agilent 5975C MSD single quadrupole mass spectrometer operated under electron ionization mode at $70 \mathrm{eV}$ in the scan range of $50-500 \mathrm{~m} / z$. For detection of the hydroxyl fatty acid products, as only authentic standards of $\alpha$ - and $\beta$-hydroxy myristic acids were obtained, samples extracted from the $\mathrm{C}_{14}$ myristic acid reactions were derivatized with an equal volume of $\mathrm{N}, \mathrm{O}$ bis(trimethylsilyl)trifluoroacetamide (BSTFA) with $1 \%$ trimethylchlorosilane at $72{ }^{\circ} \mathrm{C}$ for $15 \mathrm{~min}$ prior to GCMS analysis. The GC-MS analysis followed the protocol developed by Rude et al. [13], except for using the Agilent J\&W DB-5MS column (i.d. $0.25 \mu \mathrm{m}$ film thickness, $50 \mathrm{~m}$ by $0.25 \mathrm{~mm}$ ). Peak identity was determined by comparison of retention time and fragmentation pattern with the authentic standard compounds where available and to the National Institute of Standards and Technology, USA mass spectral database. From the reactions using myristic acid as a substrate, we found that the sum of all products ( 1 -tridecene, $\alpha$ - and $\beta$-hydroxy myristic acids) almost accurately accounts for at least $99 \%$ of the substrate consumption. In addition, as only a minimal level of $\mathrm{H}_{2} \mathrm{O}_{2}$ relative to fatty acid substrate (slightly more than 1:1 molar ratio) was used, no overly oxidized products (such as ketones, di-hydroxyl fatty acids) were observed within the detection limit. Therefore, we quantified the percentage of hydroxylated products for all substrates by subtraction of the 1-alkene production from the total substrate consumption unless otherwise stated. For detection of nonene product from the $\mathrm{C}_{10}$ fatty acid reactions, $600 \mu \mathrm{L}$ of the reaction headspace sample was injected into the GC-MS system using a Hamilton needle syringe. The oven temperature program was as follows: $40{ }^{\circ} \mathrm{C}$ for $2 \mathrm{~min}$, then $5{ }^{\circ} \mathrm{C}$ per min to $100{ }^{\circ} \mathrm{C}$, and held for $2 \mathrm{~min}$. Quantification of the nonene product was based on the standard curve and reaction controls.

\section{Additional files}

Additional file 1: Figure S1. Protein sequence alignment of CYP-Aa162 from A. acidocaldarius (GenBank Accession Number:WP_008340313), $\mathrm{P}_{450} \mathrm{BS} \beta_{\beta}$ from Bacillus subtilis str. 168 (GenBank Accession Number: NP_388092), OleT JE from Jeotgalicoccus sp. ATCC 8456 (GenBank Accession Number: ADW41779), CYP-Sm46 (labelled as Sm46 extended) from Staphylococcus massiliensis S46 (GenBank Accession Number: EKU50422),

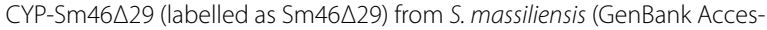
sion Number:WP_039990689) and cytochrome P450 enzymes from other Staphylococcus species such as S. agnetis (GenBank Accession Number: KFE42911), S. delphini (GenBank Accession Number:WP_019165531), S. intermedius (GenBank Accession Number:WP_019167377) and S. pseudintermedius HKU10-03 (GenBank Accession Number: ADV05454). Figure S2. SDS-PAGE showing the purified His-tagged CYP-Aa162 (lane A) and CYP-Sm46 29 (lane S). Molecular sizes of the marker bands (lane M), from top to bottom, are $180,135,100,75,63,48,35$ and $25 \mathrm{kDa}$ respectively. Figure S3. The UV-visible spectra of CYP-Sm46 $29(5 \mu \mathrm{M})$ under different conditions. (A) The purified CYP-Sm46 $\triangle 29$ was diluted in $50 \mathrm{mM} \mathrm{Na}_{3} \mathrm{PO}_{4}$ ( $p H$ 7.4) buffer containing $300 \mathrm{mM} \mathrm{NaCl}$ and $10 \%$ glycerol. Spectra are shown for the oxidized ferric form of the enzyme (orange line) and the ferrous-CO complex reduced by the indicated amount of $\mathrm{Na}_{2} \mathrm{~S}_{2} \mathrm{O}_{4}$. (B) The purified CYP-Sm46 $\triangle 29$ was diluted in $50 \mathrm{mM} \mathrm{Na}_{3} \mathrm{PO}_{4}$ buffer containing $300 \mathrm{mM} \mathrm{NaCl}$ and $10 \%$ glycerol with different buffer $\mathrm{pH}$ as indicated. Then the absorption spectra were recorded respectively for the oxidized ferric form and the ferrous- $\mathrm{CO}$ adduct reduced by $10 \mathrm{mM} \mathrm{Na}_{2} \mathrm{~S}_{2} \mathrm{O}_{4}$. The protein precipitates at buffer pH lower than 7.0. (C) A molar excess $(600 \mu \mathrm{M})$ of $\mathrm{C}_{12}$ lauric acid was pre-incubated with the enzyme at room temperature for $5 \mathrm{~min}$ before the absorption spectra were recorded. Binding of $C_{12}$ FA did not seem to induce an apparent spin-state transition of the ferric heme. The Soret peak of the $\mathrm{C}_{12}$-bound ferrous- $\mathrm{CO}$ adduct of the enzyme was still detected at $420 \mathrm{~nm}$. Figure S4. UV-visible spectra of the self-sufficient monooxygenase $\mathrm{P}_{450} \mathrm{BM}_{\mathrm{BM}}$. The substrate-bound ferric form of $\mathrm{P}_{450_{\mathrm{BM} 3}}$ (solid line) shows a Soret maximum at $\sim 416 \mathrm{~nm}$ with undistinguishable $\beta$-band and a weaker $a$-band at $570 \mathrm{~nm}$. The reduced ferrous-CO form of $\mathrm{P}^{4} 5 \mathrm{O}_{\mathrm{BM} 3}$ (dashed line) generated by the subsequent $\mathrm{NADPH}$-initiated electron transfer features a shifted Soret peak to $448 \mathrm{~nm}$. Figure S5. Effect of decoupling NADH oxidation and electron transfer on the catalytic conversion of lauric acid (LA) by CYP-Aa162 and CYPSm46 $\triangle 29$. The reactions contained 0.2 mM LA, $2.0 \mu M$ CYP-Aa162 (or 
CYP-Sm46 $\triangle 29), 3.0 \mu \mathrm{M}$ putidaredoxin reductase (PdR), $1 \mathrm{mM} \mathrm{NADH}$ in the absence and presence of $1200 \mathrm{U} \mathrm{mL}^{-1}$ catalase (Catl.). By subtracting putidaredoxin ( $\mathrm{Pdx}$ ) from the reaction system, the $\mathrm{NADH}$ oxidation was mandatorily decoupled from the Class I electron transfer chain to P450 enzymes. Any catalytic activity observed should be supported by the $\mathrm{H}_{2} \mathrm{O}_{2}$ generated from NADH oxidation and $\mathrm{O}_{2}$ reduction. The percentage conversion of $\mathrm{LA}$ was determined by calculating the substrate consumption based on GC analysis. Results shown are mean \pm SD of duplicated experiments. Figure $\mathbf{S 6}$. The ratios of free fatty acid (FFA) decarboxylation (DC) over hydroxylation (HD) by CYP-Sm46 29 against different FFA substrates. The decarboxylation activity was measured by detecting the 1-alkene yield using GC analytical method. The hydroxylation activity was estimated by subtracting the alkene production from the total substrate conversion. This indirect but more convenient method was validated with $\mathrm{C}_{14}$ myristic acid substrate by direct measurement of the BSTFA/TMCS derivatized hydroxylation products. Results are shown as mean \pm SD of duplicated experiments. Figure S7. Phylogenetic tree for CYP-Aa162, CYP-Sm 46 $\triangle 29$ and other CYP152 family members. The sequences were aligned using ClustalW. The Neighbor-joining Tree was generated using MEGA 7.0 package. Bootstrap values shown next to the branches were computed from 1000 bootstrap tests. CYP-Sm46 was found most closely related to the P450 fatty acid decarboxylase OleT $\mathrm{T}_{\text {IE }}$ (CYP152L1), while CYP-Aa162 (CYP152A8) is much closer to the P450 fatty acid hydroxylase

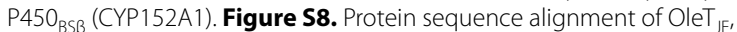
CYP-Sm46 29 , CYP-Aa162 and P450 BSB. * the only two residues that are distinct in the active sites of these four $\mathrm{P} 450$ peroxygenases, which are proposed to be important for product distribution; \#: the key catalytic residue. Figure S9. Kinetic curves of CYP-Aa162 and CYP-Sm46 229 against their optimal fatty acid substrates. (A) $C_{12}$ lauric acid substrate consumption rates by CYP-Aa162 were fitted to Hill equation; (B) 1-undecene formation rates by CYP-Sm46 $\triangle 29$ were fitted to Hill equation; (C) Solid line: the plot of 1-tridecene formation rates by CYP-Sm46 $\triangle 29$ as a function of increasing $C_{14}$ myristic acid concentrations, demonstrating substantial substrate inhibition. Dotted line: a hyperbolic curve fitted with MichaelisMenten equation after truncating the inhibited rates at high $C_{14}$ substrate concentrations. The steady state kinetic parameters were calculated using OriginPro 8.0 and are summarized in Table 2.

Additional file 2. The original gene sequence of CYP-Sm46, and the codon-optimized gene sequences of CYP-Sm46 and CYP-Aa162, as well as their corresponding amino acid sequences.

Additional file 3: Table S1. Primers used for cloning and site-directed mutagenesis.

\section{Abbreviations}

CYP or P450: cytochrome P450 enzyme; FFA: free fatty acid; LS: low-spin heme iron; CamAB: the P450cam redox partner proteins including putidaredoxin reductase and putidaredoxin; LA: lauric acid; 1-UE: 1-undecene; TB: terrific broth; IPTG: isopropyl $\beta$-D-1-thiogalactopyranoside; Ni-NTA: nickel-nitrilotriacetic acid resin; GC-MS: gas chromatography-mass spectrometry; DC: decarboxylation; HD: hydroxylation.
\end{abstract}

\section{Authors' contributions}

$S L, L F, S C, F L, H X$, and JX conceived and designed the study. HX, LN, WY, BF, YW, and $C W$ performed the experiments and analyzed the results. $H X, L F$, and $S L$ wrote the manuscript. All authors read and approved the final manuscript.

\section{Author details}

${ }^{1}$ Shandong Provincial Key Laboratory of Synthetic Biology, Qingdao Institute of Bioenergy and Bioprocess Technology, Chinese Academy of Sciences, No. 189 Songling Road, Qingdao 266101, Shandong, China. ${ }^{2}$ CAS Key Laboratory of Biofuels, Qingdao Institute of Bioenergy and Bioprocess Technology, Chinese Academy of Sciences, No. 189 Songling Road, Qingdao 266101, Shandong, China. ${ }^{3}$ Single-Cell Center, Qingdao Institute of Bioenergy and Bioprocess Technology, Chinese Academy of Sciences, No. 189 Songling Road, Qingdao 266101, Shandong, China. ${ }^{4}$ University of Chinese Academy of Sciences, Beijing 100049, China. ${ }^{5}$ Total Refinery and Chemistry, SDR/Biofuels, Tour Coupole, 2, PI. Jean Millier, 92400 Courbevoie, France.

\section{Acknowledgements}

We thank Prof. Zhiqi Cong at Qingdao Institute of Bioenergy and Bioprocess Technology, Chinese Academy of Sciences for his valuable discussion and suggestions. We are also grateful to Dr. Yousong Ding at University of Florida and Prof. Thomas Pochapsky at Rutgers University for their kind gifts of the plasmids for expression of $\mathrm{P}^{4} 5 \mathrm{~B}_{\mathrm{BM} 3}$ and $\mathrm{CamAB}$, respectively.

\section{Competing interests}

The authors declare that they have no competing interests.

\section{Availability of supporting data}

All data generated or analyzed during this study are included in this manuscript (and its Additional files 1, 2, 3).

\section{Consent for publication}

Not applicable.

\section{Ethics approval and consent to participate}

Not applicable.

\section{Funding}

This work was supported by the National Science Foundation of China (NSFC 31422002 and 31770844) and the Natural Science Foundation of Shandong Province, Grant JQ201407. This study was also carried out in the framework of the Collaboration Agreement between TOTAL and QIBEBT-CAS (Qingdao Institute of Bioenergy and Bioprocess Technology, Chinese Academy of Sciences).

\section{Publisher's Note}

Springer Nature remains neutral with regard to jurisdictional claims in published maps and institutional affiliations.

Received: 21 February 2017 Accepted: 28 August 2017

Published online: 07 September 2017

\section{References}

1. Denisov IG, Makris TM, Sligar SG, Schlichting I. Structure and chemistry of cytochrome P450. Chem Rev. 2005;105:2253-77.

2. Bernhardt R. Cytochromes P450 as versatile biocatalysts. J Biotechnol. 2006;124:128-45

3. Hrycay EG, Bandiera SM. The monooxygenase, peroxidase, and peroxygenase properties of cytochrome P450. Arch Biochem Biophys. 2012;522:71-89.

4. Grogan G. Cytochromes P450: exploiting diversity and enabling application as biocatalysts. Curr Opin Chem Biol. 2011;15:241-8.

5. Guengerich FP, Munro AW. Unusual cytochrome p450 enzymes and reactions. J Biol Chem. 2013;288:17065-73.

6. Furge LL, Guengerich FP. Cytochrome P450 enzymes in drug metabolism and chemical toxicology: an introduction. Biochem Mol Biol Educ. 2006;34:66-74.

7. Steen EJ, Kang Y, Bokinsky G, Hu Z, Schirmer A, McClure A, Del Cardayre SB, Keasling JD. Microbial production of fatty-acid-derived fuels and chemicals from plant biomass. Nature. 2010;463:559-62.

8. Liao W, Heijungs R, Huppes G. Natural resource demand of global biofuels in the anthropocene: a review. Renew Sustain Energy Rev. 2012;16:996-1003.

9. Dutta K, Daverey A, Lin J-G. Evolution retrospective for alternative fuels: first to fourth generation. Renew Energy. 2014;69:114-22.

10. Timilsina GR. Biofuels in the long-run global energy supply mix for transportation. Philos Trans A Math Phys Eng Sci. 2014;372:20120323.

11. Schirmer A, Rude MA, Li X, Popova E, del Cardayre SB. Microbial biosynthesis of alkanes. Science. 2010;329:559-62.

12. Choi YJ, Lee SY. Microbial production of short-chain alkanes. Nature. 2013;502:571-4. 
13. Rude MA, Baron TS, Brubaker S, Alibhai M, Del Cardayre SB, Schirmer A. Terminal olefin (1-alkene) biosynthesis by a novel p450 fatty acid decarboxylase from Jeotgalicoccus species. Appl Environ Microbiol. 2011;77:1718-27.

14. Rui Z, Li X, Zhu X, Liu J, Domigan B, Barr I, Cate JH, Zhang W. Microbial biosynthesis of medium-chain 1-alkenes by a nonheme iron oxidase. Proc Natl Acad Sci USA. 2014;111:18237-42.

15. Gu L, Wang B, Kulkarni A, Gehret JJ, Lloyd KR, Gerwick L, Gerwick WH, Wipf P, Hakansson K, Smith JL, Sherman DH. Polyketide decarboxylative chain termination preceded by o-sulfonation in curacin a biosynthesis. J Am Chem Soc. 2009;131:16033-5.

16. Liu Y, Wang C, Yan J, Zhang W, Guan W, Lu X, Li S. Hydrogen peroxideindependent production of alpha-alkenes by OleTJE P450 fatty acid decarboxylase. Biotechnol Biofuels. 2014;7:28.

17. Rui Z, Harris NC, Zhu X, Huang W, Zhang W. Discovery of a Family of Desaturase-Like Enzymes for 1-Alkene Biosynthesis. ACS Catal. 2015;5:7091-4.

18. Belcher J, McLean KJ, Matthews S, Woodward LS, Fisher K, Rigby SE, Nelson DR, Potts D, Baynham MT, Parker DA, et al. Structure and biochemical properties of the alkene producing cytochrome P450 OleTJE (CYP152L1) from the Jeotgalicoccus sp. 8456 bacterium. J Biol Chem. 2014;289:6535-50.

19. Grant JL, Hsieh CH, Makris TM. Decarboxylation of fatty acids to terminal alkenes by cytochrome P450 compound I. J Am Chem Soc. 2015;137:4940-3.

20. Grant JL, Mitchell ME, Makris TM. Catalytic strategy for carbon-carbon bond scission by the cytochrome P450 OleT. Proc Natl Acad Sci USA. 2016;113:10049-54.

21. Zachos I, Gassmeyer SK, Bauer D, Sieber V, Hollmann F, Kourist R. Photobiocatalytic decarboxylation for olefin synthesis. Chem Commun (Camb). 2015;51:1918-21.

22. Dennig A, Kuhn M, Tassoti S, Thiessenhusen A, Gilch S, Bulter T, Haas T, Hall M, Faber K. Oxidative decarboxylation of short-chain fatty acids to 1-alkenes. Angew Chem Int Ed Engl. 2015;54:8819-22.

23. Faponle AS, Quesne MG, de Visser SP. Origin of the regioselective fatty-acid hydroxylation versus decarboxylation by a cytochrome p450 peroxygenase: what drives the reaction to biofuel production? Chemistry (Easton). 2016;22:5478-83.

24. Amaya JA, Rutland CD, Makris TM. Mixed regiospecificity compromises alkene synthesis by a cytochrome $\mathrm{P} 450$ peroxygenase from Methylobacterium populi. J Inorg Biochem. 2016;158:11-6.

25. Yan J, Liu Y, Wang C, Han B, Li S. Assembly of lipase and P450 fatty acid decarboxylase to constitute a novel biosynthetic pathway for production of 1-alkenes from renewable triacylglycerols and oils. Biotechnol Biofuels. 2015;8:34.

26. Fang B, Xu H, Liu Y, Qi F, Zhang W, Chen H, Wang C, Wang Y, Yang W, Li S. Mutagenesis and redox partners analysis of the $\mathrm{P} 450$ fatty acid decarboxylase OleT JE. Sci Rep. 2017;7:44258.

27. Hsieh CH, Huang X, Amaya JA, Rutland CD, Keys CL, Groves JT, Austin RN, Makris TM. The enigmatic P450 decarboxylase OleT is capable of, but evolved to frustrate, oxygen rebound chemistry. Biochemistry. 2017;56:3347-57.

28. Matthews S, Belcher JD, Tee KL, Girvan HM, McLean KJ, Rigby SE, Levy CW, Leys D, Parker DA, Blankley RT, Munro AW. Catalytic determinants of alkene production by the cytochrome P450 peroxygenase OleTJE. J Biol Chem. 2017;292:5128-43.

29. Wang JB, Lonsdale R, Reetz MT. Exploring substrate scope and stereoselectivity of P450 peroxygenase OleTJE in olefin-forming oxidative decarboxylation. Chem Commun (Camb). 2016;52:8131-3.

30. Dennig A, Kurakin S, Kuhn M, Dordic A, Hall M, Faber K. Enzymatic oxidative tandem decarboxylation of dioic acids to terminal dienes. Eur J Org Chem. 2016;2016:3473-7.

31. Hsieh $\mathrm{CH}$, Makris TM. Expanding the substrate scope and reactivity of cytochrome P450 OleT. Biochem Biophys Res Commun. 2016;476:462-6.

32. Schlichting I, Berendzen J, Chu K, Stock AM, Maves SA, Benson DE, Sweet RM, Ringe D, Petsko GA, Sligar SG. The catalytic pathway of cytochrome p450cam at atomic resolution. Science. 2000;287:1615-22.

33. Hrycay EG, Bandiera SM. Monooxygenase, peroxidase and peroxygenase properties and reaction mechanisms of cytochrome P450 enzymes. Adv Exp Med Biol. 2015;851:1-61.
34. Matsunaga I, Sumimoto T, Ueda A, Kusunose E, Ichihara K. Fatty acidspecific, regiospecific, and stereospecific hydroxylation by cytochrome P450 (CYP152B1) from Sphingomonas paucimobilis: substrate structure required for alpha-hydroxylation. Lipids. 2000;35:365-71.

35. Matsunaga I, Ueda A, Fujiwara N, Sumimoto T, Ichihara K. Characterization of the ybdT gene product of Bacillus subtilis: novel fatty acid beta-hydroxylating cytochrome P450. Lipids. 1999;34:841-6.

36. Montellano PROd. Cytochrome P450: structure, mechanism, and biochemistry. 4th ed. New York: Springer International Publishing; 2015.

37. Lee DS, Yamada A, Sugimoto H, Matsunaga I, Ogura H, Ichihara K, Adachi S, Park SY, Shiro Y. Substrate recognition and molecular mechanism of fatty acid hydroxylation by cytochrome P450 from Bacillus subtilis. Crystallographic, spectroscopic, and mutational studies. J Biol Chem. 2003;278:9761-7.

38. Chang MCY, Eachus RA, Trieu W, Ro D-K, Keasling JD. Engineering Escherichia coli for production of functionalized terpenoids using plant P450s. Nat Chem Biol. 2007;3:274-7.

39. Petersen TN, Brunak S, von Heijne G, Nielsen H. SignalP 4.0: discriminating signal peptides from transmembrane regions. Nat Methods. 2011;8:785-6.

40. Krogh A, Larsson B, von Heijne G, Sonnhammer EL. Predicting transmembrane protein topology with a hidden Markov model: application to complete genomes. J Mol Biol. 2001;305:567-80.

41. Kall L, Krogh A, Sonnhammer EL. A combined transmembrane topology and signal peptide prediction method. J Mol Biol. 2004;338:1027-36.

42. Girvan HM, Marshall KR, Lawson RJ, Leys D, Joyce MG, Clarkson J, Smith WE, Cheesman MR, Munro AW. Flavocytochrome P450 BM3 mutant A264E undergoes substrate-dependent formation of a novel heme iron ligand set. J Biol Chem. 2004;279:23274-86.

43. Ogura H, Nishida CR, Hoch UR, Perera R, Dawson JH, Ortiz de Montellano PR. EpoK, a cytochrome P450 involved in biosynthesis of the anticancer agents epothilones A and B. Substrate-mediated rescue of a P450 enzyme. Biochemistry. 2004;43:14712-21.

44. Perera R, Sono M, Sigman JA, Pfister TD, Lu Y, Dawson JH. Neutral thiol as a proximal ligand to ferrous heme iron: implications for heme proteins that lose cysteine thiolate ligation on reduction. Proc Natl Acad Sci USA. 2003; 100:3641-6.

45. Sun Y, Zeng W, Benabbas A, Ye X, Denisov I, Sligar SG, Du J, Dawson JH, Champion PM. Investigations of heme ligation and ligand switching in cytochromes p450 and p420. Biochemistry. 2013;52:5941-51.

46. Austin RN, Groves JT. Alkane-oxidizing metalloenzymes in the carbon cycle. Metallomics. 2011;3:775-87.

47. Noble MA, Miles CS, Chapman SK, Lysek DA, MacKay AC, Reid GA, Hanzlik RP, Munro AW. Roles of key active-site residues in flavocytochrome P450 BM3. Biochem J. 1999;339(Pt 2):371-9.

48. Lin Y, Lu P, Tang C, Mei Q, Sandig G, Rodrigues AD, Rushmore TH, Shou M. Substrate inhibition kinetics for cytochrome P450-catalyzed reactions. Drug Metab Dispos. 2001;29:368-74.

49. Chen B, Lee DY, Chang MW. Combinatorial metabolic engineering of Saccharomyces cerevisiae for terminal alkene production. Metab Eng. 2015:31:53-61.

50. Yang SJ, Rice KC, Brown RJ, Patton TG, Liou LE, Park YH, Bayles KW. A LysR-type regulator, $\mathrm{CidR}$, is required for induction of the Staphylococcus aureus cidABC operon. J Bacteriol. 2005;187:5893-900.

51. McLaughlin JR, Murray CL, Rabinowitz JC. Unique features in the ribosome binding site sequence of the gram-positive Staphylococcus aureus b-lactamase gene. J Biol Chem. 1981;256:11283-91.

52. Munro AW, Lindsay JG, Coggins JR, Kelly SM, Price NC. Analysis of the structural stability of the multidomain enzyme flavocytochrome P-450 BM3. Biochim Biophys Acta. 1996;1296:127-37.

53. Manna SK, Mazumdar S. Reversible inactivation of cytochrome P450 by alkaline earth metal ions: auxiliary metal ion induced conformation change and formation of inactive P420 species in CYP101. J Inorg Biochem. 2008;102:1312-21.

54. Panicco P, Astuti Y, Fantuzzi A, Durrant JR, Gilardi G. P450 versus P420: correlation between cyclic voltammetry and visible absorption spectroscopy of the immobilized heme domain of cytochrome P450 BM3. J Phys Chem B. 2008;112:14063-8.

55. Hiner AN, Raven EL, Thorneley RN, Garcia-Canovas F, Rodriguez-Lopez $J$ N. Mechanisms of compound I formation in heme peroxidases. J Inorg Biochem. 2002;91:27-34. 
56. Lin JH, Lu AY. Role of pharmacokinetics and metabolism in drug discovery and development. Pharmacol Rev. 1997;49:403-49.

57. Korzekwa KR, Krishnamachary N, Shou M, Ogai A, Parise RA, Rettie AE, Gonzalez FJ, Tracy TS. Evaluation of atypical cytochrome P450 kinetics with two-substrate models: evidence that multiple substrates can simultaneously bind to cytochrome P450 active sites. Biochemistry. 1998:37:4137-47.

58. Shou M, Mei Q, Ettore MW Jr, Dai R, Baillie TA, Rushmore TH. Sigmoidal kinetic model for two co-operative substrate-binding sites in a cytochrome P450 3A4 active site: an example of the metabolism of diazepam and its derivatives. Biochem J. 1999;340(Pt 3):845-53.

59. Houston JB, Galetin A. Modelling atypical CYP3A4 kinetics: principles and pragmatism. Arch Biochem Biophys. 2005:433:351-60.

60. Ma L, Du L, Chen H, Sun Y, Huang S, Zheng X, Kim E-S, Li S. Reconstitution of the in vitro activity of the cyclosporine-specific $\mathrm{P} 450$ hydroxylase from Sebekia benihana and development of a heterologous whole-cell biotransformation system. Appl Environ Microbiol. 2015;81:6268-75.

61. Fujishiro T, Shoji O, Kawakami N, Watanabe T, Sugimoto H, Shiro Y, Watanabe Y. Chiral-substrate-assisted stereoselective epoxidation catalyzed by $\mathrm{H}_{2} \mathrm{O}_{2}$-dependent cytochrome P450 SPa: Chem Asian J. 2012;7:2286-93.

62. Onoda $\mathrm{H}$, Shoji $\mathrm{O}$, Watanabe $\mathrm{Y}$. Acetate anion-triggered peroxygenation of non-native substrates by wild-type cytochrome P450s. Dalton Trans. 2015;44:15316-23.
63. Shoji O, Fujishiro T, Nakajima H, Kim M, Nagano S, Shiro Y, Watanabe Y. Hydrogen peroxide dependent monooxygenations by tricking the substrate recognition of cytochrome P450BSbeta. Angew Chem Int Ed Engl. 2007:46:3656-9.

64. Ho SN, Hunt HD, Horton RM, Pullen JK, Pease LR. Site-directed mutagenesis by overlap extension using the polymerase chain reaction. Gene. 1989;77:51-9.

65. Wang ZJ, Peck NE, Renata H, Arnold FH. Cytochrome P450-catalyzed insertion of carbenoids into N-H bonds. Chem Sci. 2014;5:598-601.

66. Guengerich FP, Martin MV, Sohl CD, Cheng Q. Measurement of cytochrome P450 and NADPH-cytochrome P450 reductase. Nat Protoc. 2009:4:1245-51.

67. Berry EA, Trumpower BL. Simultaneous determination of hemes $a, b$, and c from pyridine hemochrome spectra. Anal Biochem. 1987;161:1-15.

68. Guan W, Zhao H, Lu X, Wang C, Yang M, Bai F. Quantitative analysis of fatty-acid-based biofuels produced by wild-type and genetically engineered cyanobacteria by gas chromatography-mass spectrometry. J Chromatogr A. 2011;1218:8289-93.

\section{Submit your next manuscript to BioMed Central and we will help you at every step:}

- We accept pre-submission inquiries

- Our selector tool helps you to find the most relevant journal

- We provide round the clock customer support

- Convenient online submission

- Thorough peer review

- Inclusion in PubMed and all major indexing services

- Maximum visibility for your research

Submit your manuscript at www.biomedcentral.com/submit
() Biomed Central 